Check for

Cite as

Nano-Micro Lett.

(2020) $12: 56$

Received: 9 November 2019

Accepted: 15 January 2020

Published online: 18 February 2020

(C) The Author(s) 2020

\section{Layered Birnessite Cathode with a Displacement/ Intercalation Mechanism for High-Performance Aqueous Zinc-Ion Batteries}

\author{
Xian-Zhi Zhai ${ }^{1,2}$, Jin $\mathrm{Qu}^{1}{ }^{凶}$, Shu-Meng $\mathrm{Hao}^{2}$, Ya-Qiong Jing ${ }^{1}$, Wei Chang ${ }^{2}$, Juan Wang ${ }^{1}$, \\ Wei $\mathrm{Li}^{1}$, Yasmine Abdelkrim ${ }^{1}$, Hongfu Yuan ${ }^{1}$, Zhong-Zhen $\mathrm{Yu}^{1,2}$ 叫 \\ \in Qu, qujin@mail.buct.edu.cn; Zhong-Zhen Yu, yuzz@mail.buct.edu.cn \\ 1 State Key Laboratory of Organic-Inorganic Composites, College of Materials Science and Engineering, \\ Beijing University of Chemical Technology, Beijing 100029, People's Republic of China \\ 2 Beijing Key Laboratory of Advanced Functional Polymer Composites, Beijing University of Chemical \\ Technology, Beijing 100029, People's Republic of China
}

\title{
HIGHLIGHTS
}

- A layered sodium-ion/crystal water co-intercalated $\mathrm{Na}_{0.55} \mathrm{Mn}_{2} \mathrm{O}_{4} \cdot 0.57 \mathrm{H}_{2} \mathrm{O}(\mathrm{NMOH})$ cathode is synthesized successfully with a selectively etching method for zinc-ion batteries.

- A displacement/intercalation mechanism is confirmed in the Mn-based cathode for the first time.

- The NMOH cathode delivers a competitive reversible capacity of $201.6 \mathrm{~mA} \mathrm{~h} \mathrm{~g}^{-1}$ at $500 \mathrm{~mA} \mathrm{~g}^{-1}$ after 400 cycles.

\begin{abstract}
Mn-based rechargeable aqueous zinc-ion batteries (ZIBs) are highly promising because of their high operating voltages, attractive energy densities, and eco-friendliness. However, the electrochemical performances of Mn-based cathodes usually suffer from their serious structure transformation upon charge/discharge cycling. Herein, we report a layered sodium-ion/crystal water co-intercalated Birnessite cathode with the formula of $\mathrm{Na}_{0.55} \mathrm{Mn}_{2} \mathrm{O}_{4} \cdot 0.57 \mathrm{H}_{2} \mathrm{O}(\mathrm{NMOH})$ for high-performance aqueous ZIBs. A displacement/intercalation electrochemical mechanism was confirmed in the Mn-based cathode for the first time. $\mathrm{Na}^{+}$and crystal water enlarge the interlayer distance to enhance the insertion of $\mathrm{Zn}^{2+}$, and some sodium ions are replaced with $\mathrm{Zn}^{2+}$ in the first cycle to further stabilize the layered structure for subsequent reversible $\mathrm{Zn}^{2+} / \mathrm{H}^{+}$insertion/extraction, resulting in exceptional

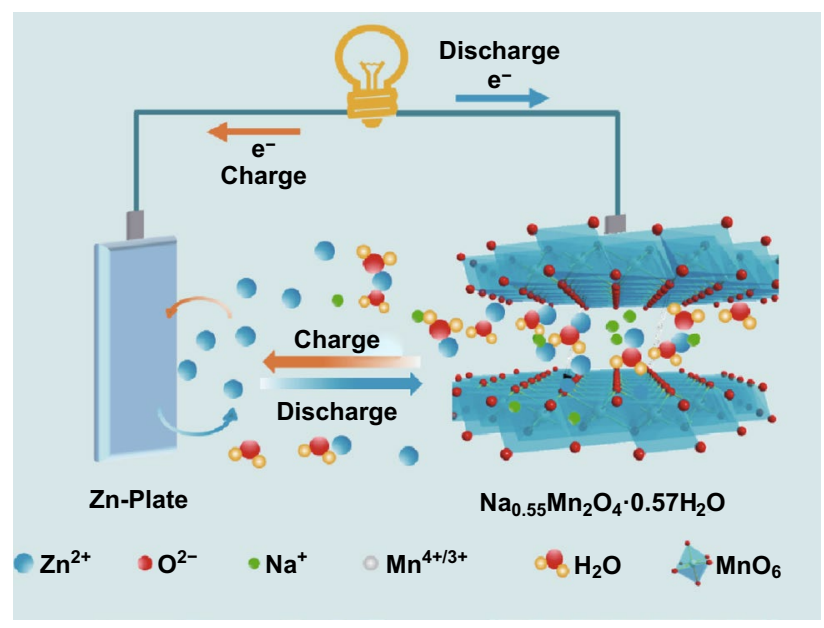
specific capacities and satisfactory structural stabilities. Additionally, a pseudo-capacitance derived from the surface-adsorbed $\mathrm{Na}^{+}$also contributes to the electrochemical performances. The NMOH cathode not only delivers high reversible capacities of 389.8 and $87.1 \mathrm{~mA} \mathrm{~h} \mathrm{~g}^{-1}$ at current densities of 200 and $1500 \mathrm{~mA} \mathrm{~g}^{-1}$, respectively, but also maintains a good long-cycling performance of $201.6 \mathrm{~mA} \mathrm{~h} \mathrm{~g}^{-1}$ at a high current density of $500 \mathrm{~mA} \mathrm{~g}^{-1}$ after 400 cycles, which makes the NMOH cathode competitive for practical applications.
\end{abstract}

KEYWORDS Zinc-ion batteries; Birnessite; Sodium ions; Layered structure; Crystal water 


\section{Introduction}

Eco-friendly energy storage technologies continue to attract wide attentions due to the serious environmental pollution and energy consumption [1-8]. Rechargeable aqueous metal-ion $\left(\mathrm{Li}^{+}, \mathrm{Na}^{+}, \mathrm{Zn}^{2+}, \mathrm{Mg}^{2+}, \mathrm{Ca}^{2+}\right.$, etc. $)$ batteries exhibit considerable advantages for grid-scale energy storage technologies, due to their eco-friendliness, low-cost, and 100-1000 times higher ionic conductivities of aqueous electrolytes than those of organic electrolytes [1, 9-12]. Recently, much effort has been devoted to zinc-ion batteries (ZIBs) because of their high safety with aqueous electrolytes, high abundance of zinc element, and the low redox potential of $\mathrm{Zn} / \mathrm{Zn}^{2+}$ at $-0.76 \mathrm{~V}$ vs SHE [13-15]. Various materials of Prussian blue analogues (PBAs), V-based compounds, and Mn-based materials have been utilized as cathodes for zinc-ion storage. PBAs have high output operation voltages, but their low capacities hinder their further developments $[16,17]$. Although layered V-based compounds, such as $\mathrm{VS}_{2}$ [18], $\mathrm{H}_{2} \mathrm{~V}_{3} \mathrm{O}_{8}$ [19], and $\mathrm{Mg}_{x} \mathrm{~V}_{2} \mathrm{O}_{5} \cdot n \mathrm{H}_{2} \mathrm{O}$ [20], exhibit presentable electrochemical performances for aqueous ZIBs, the low operation voltage, high cost, and high toxicity of vanadium impede their wide applications [21]. Given the high theoretical capacities, low-cost, and high-voltage platforms, Mn-based materials are competitive for highperformance cathodes of ZIBs. Various Mn-based materials have been reported, such as $\alpha$ - [22, 23], $\beta$ - [24], $\gamma$-phase [25], and other types [26-28] of manganese dioxide, spinel-type $\mathrm{ZnMn}_{2} \mathrm{O}_{4}[14,29,30]$, and $\mathrm{MgMn}_{2} \mathrm{O}_{4}$ [31]. However, the development of the Mn-based cathode materials is limited by low specific capacity or poor cyclability, ascribing to the irreversible phase transformation. Therefore, it is still on the way to find suitable Mn-based cathodes.

The reported Mn-based cathodes usually have two types of crystal structures: tunnel structure and layered structure. The tunnel structure is less favor of intercalation and diffusion of zinc ions than the layered structure on the basis of zinc-ion insertion/extraction mechanisms [20], so layered Mnbased cathodes would be more beneficial for aqueous ZIBs. For example, Qian et al. [32] reported an aqueous ZIB with a layered $\delta-\mathrm{MnO}_{2}$ cathode, exhibiting a specific capacity of $133 \mathrm{~mA} \mathrm{~h} \mathrm{~g}^{-1}$ at the current density of $100 \mathrm{~mA} \mathrm{~g}^{-1}$. Kim et al. [33] also fabricated a cell with a $\delta-\mathrm{MnO}_{2}$ cathode, presenting a discharge capacity of $250 \mathrm{~mA} \mathrm{~h} \mathrm{~g}^{-1}$ at a low current density of $83 \mathrm{~mA} \mathrm{~g}^{-1}$ with a high Coulombic efficiency close to $100 \%$. However, a drawback of the layered $\delta-\mathrm{MnO}_{2}$ is its irreversible phase transformation to other phases (e.g., $\mathrm{ZnO}$, $\mathrm{MnO}$, and $\mathrm{MnOOH}$ ), causing a significantly volume change of the active materials and thus resulting in capacity decay and low specific capacity. Besides, the tremendous electrostatic interaction between zinc ions and host materials usually leads to sluggish diffusion of zinc ions, limiting the development of ZIBs [19]. Fortunately, alkali metal ions of $\mathrm{Na}^{+}, \mathrm{K}^{+}$, and $\mathrm{Li}^{+}$, and crystal water could serve as pillars to stabilize the layered structure and improve the interlayer distance and, hence, benefit the diffusion of guest ions in electrode materials [34-39]. For example, Mai et al. [40] demonstrated a $\mathrm{Na}_{0.33} \mathrm{~V}_{2} \mathrm{O}_{5}$ cathode, in which the sodium ions stabilized the layered structure and improved the electronic conductivity for high-performance ZIBs. However, the role of alkali metal ions or crystal water in Mn-based cathode of ZIBs has been rarely studied.

Herein, layered sodium-ion/crystal water co-intercalated Birnessite with the formula of $\mathrm{Na}_{0.55} \mathrm{Mn}_{2} \mathrm{O}_{4} \cdot 0.57 \mathrm{H}_{2} \mathrm{O}$ $(\mathrm{NMOH})$ is fabricated by rearranging $\mathrm{MnO}_{6}$ octahedrons with sodium ions and water molecules via selectively etching the silica tetrahedrons of manganese silicate with $\mathrm{NaOH}$ solution. The resultant $\mathrm{NMOH}$ is used as the cathode material of aqueous ZIBs. As a Mn-based cathode, the NMOH is subjected to a displacement/intercalation electrochemical mechanism: Sodium ions and crystal water could enlarge the interlayer distance to speed up the transport of zinc ions, and the partial substitution of $\mathrm{Na}^{+}$with $\mathrm{Zn}^{2+}$ in the first cycle could support the layered structure, facilitating subsequent reversible $\mathrm{Zn}^{2+}$ / $\mathrm{H}^{+}$insertion/extraction. Additionally, the surface-adsorbed sodium ions also contribute to the pseudo-capacitance. As a result, the NMOH electrode of ZIBs exhibits a high specific capacity of $389.8 \mathrm{~mA} \mathrm{~h} \mathrm{~g}^{-1}$ at a current density of $200 \mathrm{~mA} \mathrm{~g}^{-1}$, and a satisfactory long-term cycle performance with a high capacity of $201.6 \mathrm{~mA} \mathrm{~h} \mathrm{~g}^{-1}$ at $500 \mathrm{~mA} \mathrm{~g}^{-1}$ after 400 cycles. The roles of sodium ions and crystal water in the Mn-based cathode of ZIBs, and the synergy between sodium ions and crystal water are studied in detail. The replacement/intercalation reaction mechanism is also elucidated.

\section{Experimental Section}

\subsection{Materials}

Zinc sulfate $\left(\mathrm{ZnSO}_{4} \cdot \mathrm{H}_{2} \mathrm{O}, 99.9 \%\right)$, sodium sulfate $\left(\mathrm{Na}_{2} \mathrm{SO}_{4}\right.$, 99.9\%), and manganese sulfate $\left(\mathrm{MnSO}_{4} \cdot \mathrm{H}_{2} \mathrm{O}, 99.9 \%\right)$ were purchased from Aladdin (China). Sodium silicate 
$\left(\mathrm{Na}_{2} \mathrm{SiO}_{3} \cdot 9 \mathrm{H}_{2} \mathrm{O}\right)$ was obtained from Xilong Scientific Co., Ltd (China). Zn foil (99.98\%) and titanium foil (99.8\%) were provided by Alfar Aesar Chemicals (China). Manganese chloride tetrahydrate $\left(\mathrm{MnCl}_{2} \cdot 4 \mathrm{H}_{2} \mathrm{O}, 99 \%\right)$, sodium hydroxide $(\mathrm{NaOH})$, and potassium permanganate $\left(\mathrm{KMnO}_{4}\right)$ were supplied by Beijing Chemical Factory (China). All the chemicals were used as received.

\subsection{Synthesis of $\mathrm{Mn}_{x} \mathrm{Si}_{y} \mathrm{O}_{z}$}

In a typical synthesis of $\mathrm{Mn}_{x} \mathrm{Si}_{y} \mathrm{O}_{z}$ (MSO), $3.2 \mathrm{mmol}$ of sodium silicate was dissolved in $40 \mathrm{~mL}$ of deionized (DI) water as solution A, while $3.2 \mathrm{mmol}$ of manganese dichloride tetrahydrate was dissolved in $60 \mathrm{~mL}$ of deionized water as solution B. After mixing the two solutions under stirring for $60 \mathrm{~min}$ at room temperature, the resultant MSO was centrifuged, washed thoroughly using DI water and ethanol several times, and dried at $80{ }^{\circ} \mathrm{C}$ for $10 \mathrm{~h}$ in air.

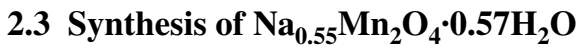

Typically, the synthesized $\mathrm{Mn}_{x} \mathrm{Si}_{y} \mathrm{O}_{z}$ was dispersed in $2 \mathrm{M}$ of sodium hydroxide solution, and the suspension was reacted under stirring in a water bath at $90{ }^{\circ} \mathrm{C}$ for $12 \mathrm{~h}$ to fabricate $\mathrm{Na}_{0.55} \mathrm{Mn}_{2} \mathrm{O}_{4} \cdot 0.57 \mathrm{H}_{2} \mathrm{O}(\mathrm{NMOH})$. The resulting $\mathrm{NMOH}$ was collected by centrifugation, washed with deionized water and ethanol for several times, and dried at $60^{\circ} \mathrm{C}$ for $12 \mathrm{~h}$.

\subsection{Synthesis of $\delta-\mathrm{MnO}_{2}$}

To synthesize the $\delta-\mathrm{MnO}_{2}$ powder, the $\mathrm{KMnO}_{4}$ was annealed at $350{ }^{\circ} \mathrm{C}$ for $5 \mathrm{~h}$ with a heating speed of $5{ }^{\circ} \mathrm{C} \mathrm{min}{ }^{-1}$ under an argon atmosphere [33]. Then, the solid resultant was washed with deionized water, then collected by centrifugation, and finally dried at $60{ }^{\circ} \mathrm{C}$ for $12 \mathrm{~h}$.

\subsection{Characterization}

Microstructures of MSO, $\mathrm{NMOH}$, and electrode were analyzed using transmission electron microscopy (TEM, JEOL JEM-1011), scanning electron microscopy (SEM, Hitachi S4700), and high-resolution TEM (HRTEM, JEOL JEM3010). Crystal structures of active materials were investigated with a Rigaku D/Max 2500 X-ray diffractometer
(XRD) using a $\mathrm{Cu} \mathrm{K} \alpha$ radiation. Compositions of the $\mathrm{NMOH}$ were measured by a Thermo VG RSCAKAB 250 high-resolution X-ray photoelectron spectroscopy (XPS). Thermal stability of NMOH was carried out on a TA Q50 thermogravimetric analyzer (TGA) at a heating speed of $10{ }^{\circ} \mathrm{C} \mathrm{min}^{-1}$ under an argon atmosphere. Specific surface area was measured based on $\mathrm{N}_{2}$ adsorption/desorption isotherms with a JW-BK132F (JWGB SCI \& TECH) analyzer. Inductively coupled plasma atomic emission spectroscopy (ICP-AES) was performed on ICAP6300 Radial. For the ex situ XRD measurements, the cathodes obtained at specific voltages were washed thoroughly with distilled water and ethanol and these electrodes were then dried at $60^{\circ} \mathrm{C}$ for $10 \mathrm{~h}$ in vacuum.

\subsection{Electrochemical Characterization}

Electrochemical measurements of the $\mathrm{NMOH}$ were performed with CR2032 coin-type cells assembled in air. To fabricate working electrode, the NMOH, super-P, RGO, and poly(vinylidene fluoride) with a mass ratio of 70:15:5:10 were mixed by ball milling with $N$-methyl-2-pyrrolidone as the solvent. The obtained slurry was coated onto a Ti foil and vacuum-dried at $80^{\circ} \mathrm{C}$ for $12 \mathrm{~h}$. The loading mass of the active material was $\sim 1.0-1.5 \mathrm{mg} \mathrm{cm}^{-2}$. Zinc foil and glass fiber membrane were used as the anode and separator, respectively. A $2 \mathrm{M} \mathrm{ZnSO}_{4}$ with/without $0.2 \mathrm{M} \mathrm{MnSO}_{4}$ aqueous solution was used as the electrolyte. The charge/ discharge experiments were performed on a Land BT2000 battery test system (China) at room temperature. Cyclic voltammetry $(\mathrm{CV})$ and electrochemical impedance spectroscopy (EIS, $100 \mathrm{kHz}$ to $0.01 \mathrm{~Hz}$ ) were obtained on a CHI $760 \mathrm{E}$ electrochemical workstation.

\section{Results and Discussion}

Figure 1a shows XRD pattern of the as-synthesized NMOH. Different from the amorphous phase of $\mathrm{Mn}_{x} \mathrm{Si}_{y} \mathrm{O}_{z}$ (MSO) with a broad peak (Fig. S1a), the NMOH has obvious sharp peaks, belonging to high-purity layered Na-rich Birnessite of $\mathrm{Na}_{0.55} \mathrm{Mn}_{2} \mathrm{O}_{4} \cdot x \mathrm{H}_{2} \mathrm{O}$ (monoclinic phase, JCPDS No. 43-1456) with the $\mathrm{C} 2 / \mathrm{m}$ space group [41, 42]. As illustrated in Fig. 1b, the layered structure is constructed by the sheets consisting of two-dimensional edge-sharing $\mathrm{MnO}_{6}$ octahedrons, in which $\mathrm{Mn}$ and $\mathrm{O}$ atoms occupy $2 \mathrm{a}$ and $4 \mathrm{i}$ sites, respectively $[42,43]$. The interlayer spacing of the layered 
NMOH determined from its (001) plane at $12.3^{\circ}$ is $7.25 \AA$. Many sodium ions do exist with significant amounts of crystal water in the intra-gallery to stabilize the layered structure and expand the space between the (001) planes, which could facilitate the transport and diffusion of zinc ions during the charge/discharge process, inhibit the manganese ion dissolution caused by the Jahn-Teller effect [31, 37, 38], and improve the performances of the ZIBs.

The $\delta-\mathrm{MnO}_{2}$ particles (monoclinic phase, JCPDS No. 42-1317) with the layered structure are fabricated by the thermal decomposition of $\mathrm{KMnO}_{4}$ (Fig. S1b) [33, 43] and exhibit an irregular morphology (Fig. S1c). The XRD pattern (Fig. S1d) unveils that the interlayer distance of $\mathrm{NMOH}$ is larger than that of the $\delta-\mathrm{MnO}_{2}$, resulting from the presence of $\mathrm{Na}^{+}$and crystal water between the adjacent layers of $\mathrm{NMOH}$. Figure S2a shows TGA curve of NMOH measured under an argon atmosphere from room temperature up to $1000{ }^{\circ} \mathrm{C}$. The mass loss in the range of $27-100{ }^{\circ} \mathrm{C}$ derives from the removal of surface free water, while the mass loss of $5.24 \mathrm{wt} \%$ from 100 to $300{ }^{\circ} \mathrm{C}$ is assigned to the removal of crystal water. Therefore, the $x$ value in $\mathrm{Na}_{0.55} \mathrm{Mn}_{2} \mathrm{O}_{4} \cdot x \mathrm{H}_{2} \mathrm{O}$ could be calculated as $\sim 0.57$.
To explore the compositions and valence states of the NMOH, Fig. 1c presents the XPS survey spectrum of $\mathrm{NMOH}$, showing the peaks of $\mathrm{Na}, \mathrm{Mn}$, and $\mathrm{O}$. The high-resolution $\mathrm{O} 1 s$ spectrum (Fig. 1d) displays three fitting peaks at 529.2, 531.6, and $532.9 \mathrm{eV}$ corresponding to $\mathrm{Mn}-\mathrm{O}-\mathrm{M}$, $\mathrm{Mn}-\mathrm{O}-\mathrm{H}$, and $\mathrm{H}-\mathrm{O}-\mathrm{H}$ bonds, respectively [23, 44]. The presence of sodium ions is further verified by the high-resolution $\mathrm{Na} 1 s$ spectrum with the binding energy of $1070.6 \mathrm{eV}$ (Fig. 1e) [41, 45]. The two peaks of Mn $2 p$ (Fig. 1f) located at 641.9 and $653.8 \mathrm{eV}$ are attributed to $\mathrm{Mn} 2 p_{3 / 2}$ and $\mathrm{Mn}$ $2 p_{1 / 2}$, respectively [41, 44]. Additionally, the four fitting peaks indicate that $\mathrm{Mn}^{4+}$ and $\mathrm{Mn}^{3+}$ ions are dominant in the $\mathrm{NMOH}$ to keep the electrical neutrality, because of the presence of sodium ions. The coexistence of $\mathrm{Mn}^{4+}$ and $\mathrm{Mn}^{3+}$ is also consistent with the average valence of $\mathrm{Mn}$ in the $\mathrm{NMOH}$ (ca. + 3.73). All these results confirm the successful fabrication of layered sodium-ion/crystal water co-intercalated $\mathrm{Na}_{0.55} \mathrm{Mn}_{2} \mathrm{O}_{4} \cdot 0.57 \mathrm{H}_{2} \mathrm{O}$.

Figure 2a shows the TEM image of MSO. Apparently, the MSO is composed of many worm-like nanoparticles. As a typical metal silicate, the crystal structure of MSO should contain $\mathrm{MnO}_{6}$ octahedrons and silica tetrahedrons
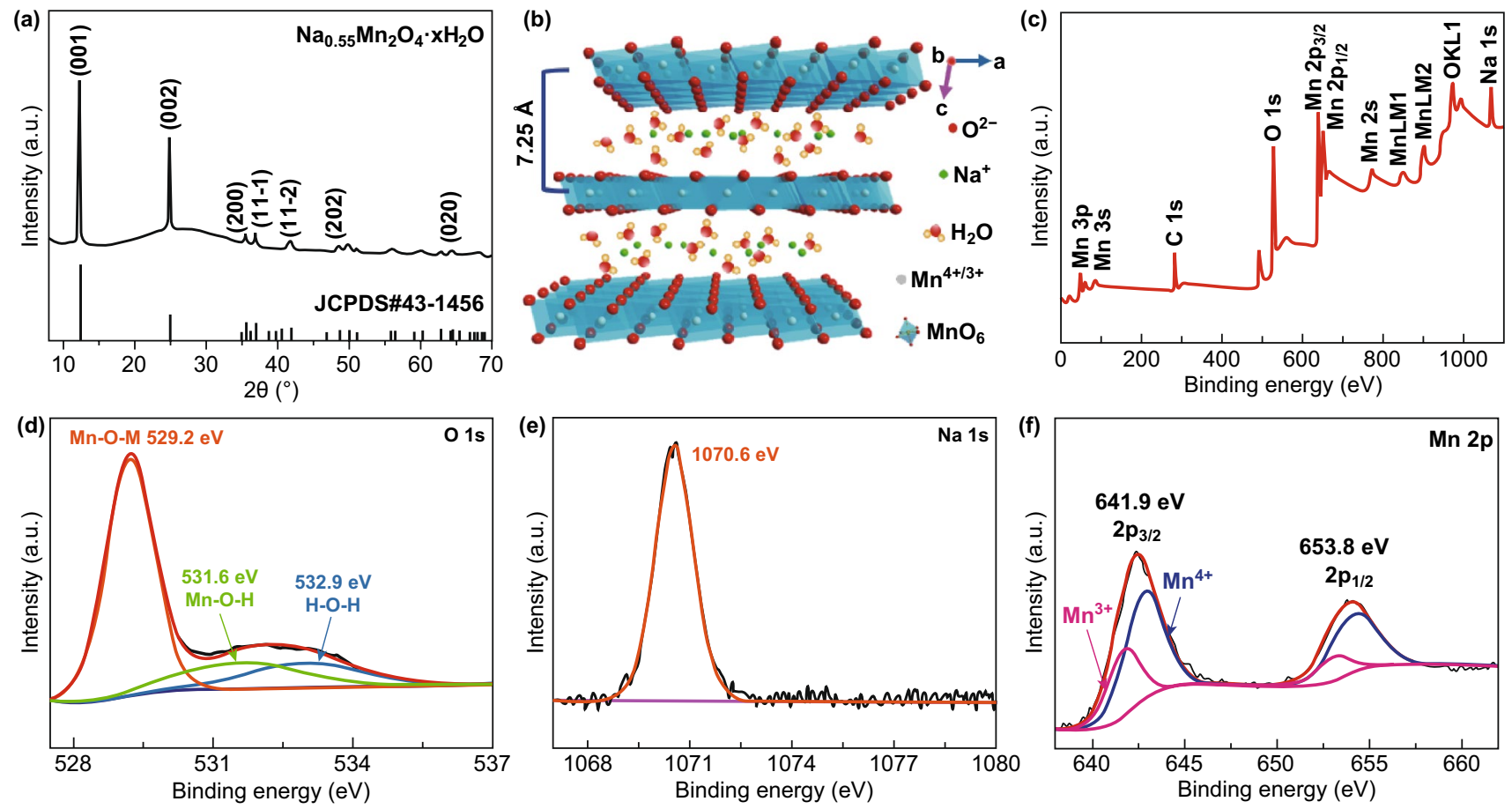

Fig. 1 a XRD pattern of NMOH. b Illustration of crystal structure of $\mathrm{Na}_{0.55} \mathrm{Mn}_{2} \mathrm{O}_{4} \cdot x \mathrm{H}_{2} \mathrm{O}$. XPS spectra of NMOH: c survey scan, d O $1 s$ spectrum, e Na $1 s$ spectrum, and f Mn $2 p$ spectrum 
$[46,47]$. During the etching treatment, silica tetrahedrons are selectively removed by the $\mathrm{NaOH}$ solution, while the residual $\mathrm{MnO}_{6}$ octahedrons rearrange with sodium ions and water molecules to form $\mathrm{NMOH}$ nanosheets with smooth surface (Fig. 2b). Some black nanoparticles are formed within the etching time of $9 \mathrm{~h}$ (Fig. S1e-h). XRD patterns of the $\mathrm{NMOH}$ with different etching time show that these black nanoparticles should be indexed to the phase of $\mathrm{Mn}_{3} \mathrm{O}_{4}$ (Fig. S1a). However, these black nanoparticles would completely disappear after etching twelve hours to form pure NMOH nanosheets (Fig. S1i, j). The $\mathrm{N}_{2}$ adsorption-desorption analysis is conducted to identify the BET specific surface area of the $\mathrm{NMOH}$ and $\delta-\mathrm{MnO}_{2}$ (Fig. S2b). The layered $\mathrm{NMOH}$ has a higher specific surface area $\left(81.6 \mathrm{~m}^{2} \mathrm{~g}^{-1}\right)$ than that of $\delta-\mathrm{MnO}_{2}\left(13.5 \mathrm{~m}^{2} \mathrm{~g}^{-1}\right)$. Meanwhile, abundant mesopores with a relatively narrow pore-size distribution of $\sim 8 \mathrm{~nm}$ provide a large number of active sites for storage of zinc ions and enhance the contact area of the active material with the electrolyte, promoting the transport and diffusion of zinc ions [41, 48, 49]. In addition, the presence of these mesopores is favorable for regulating the volume change caused by the insertion/ extraction of zinc ions during the discharge/charge process, ensuring a satisfactory cyclability and a high specific capacity $[3,50]$.

TEM image of NMOH (Fig. 2c) shows typical nanosheets with length and width of approximately $100-500 \mathrm{~nm}$, which is consistent with its SEM results. The EDS mapping reveals that the $\mathrm{Na}, \mathrm{Mn}$, and $\mathrm{O}$ elements are uniformly distributed on the NMOH nanosheets (Fig. S3). The plenty crystal boundaries and mesopores displayed by the white circles (Fig. 2d) could facilitate the insertion/extraction of zinc ions from the edge. Besides, the clear lattice spacings of 0.500 , 0.282 , and $0.259 \mathrm{~nm}$ match well with the inter-planar distances of the (100), (010), and (20-1) planes, respectively (Fig. 2e). The corresponding SAED pattern also confirms
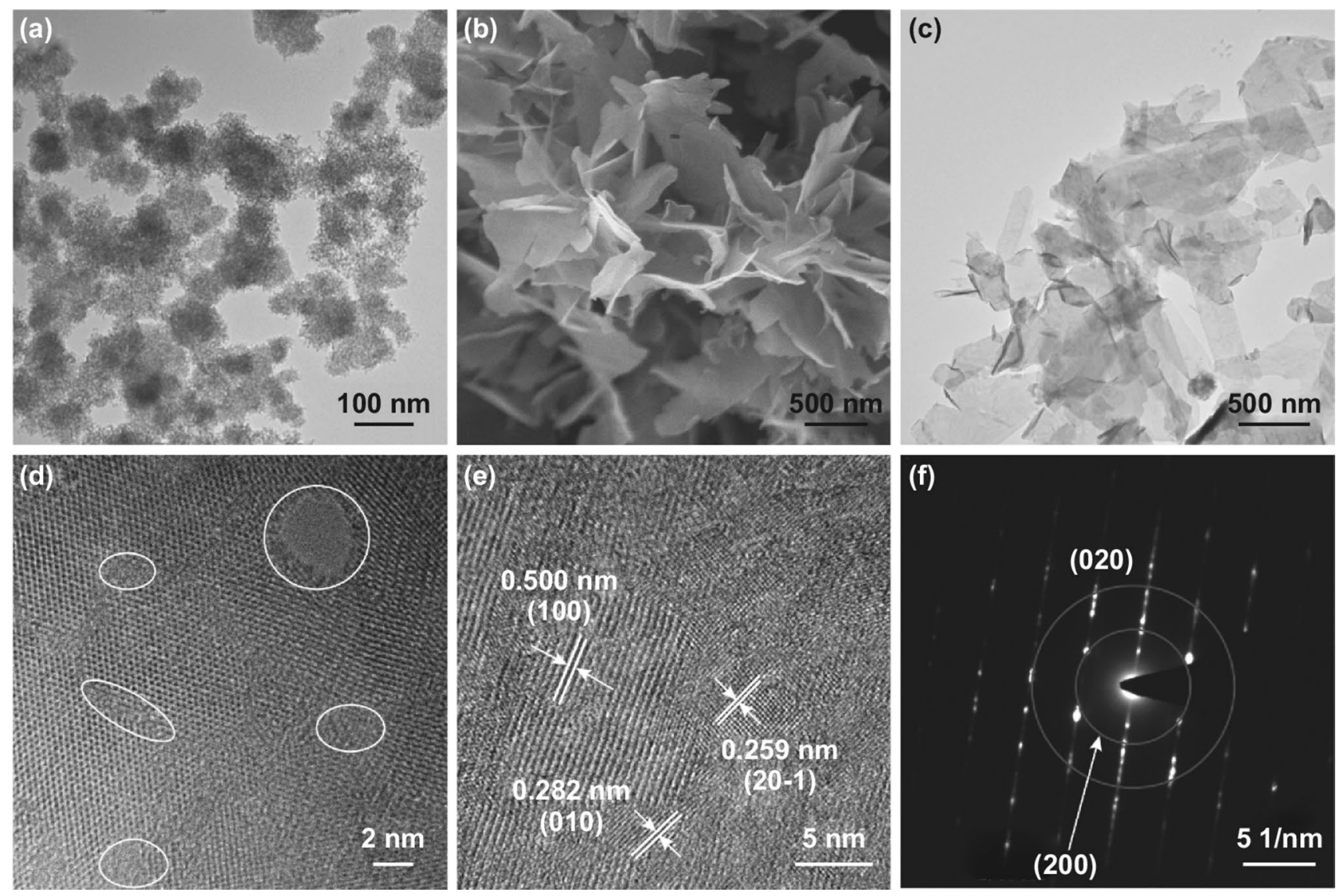

Fig. 2 a TEM image of $\mathrm{Mn}_{x} \mathrm{Si}_{y} \mathrm{O}_{z}$. b SEM image, c TEM image, d, e HRTEM images, and $\mathbf{f}$ corresponding SAED pattern of $\mathrm{Na}_{0.55} \mathrm{Mn}_{2} \mathrm{O}_{4} \cdot 0.57 \mathrm{H}_{2} \mathrm{O}$ 
the polycrystalline nature of the NMOH (Fig. 2f). These results verify the mesoporous and layered structure of the $\mathrm{NMOH}$ nanosheets.

The zinc-ion storage performances of $\mathrm{NMOH}$ nanosheets in an aqueous electrolyte $\left(2 \mathrm{M} \mathrm{ZnSO}_{4}+0.2 \mathrm{M} \mathrm{MnSO}_{4}\right)$ are investigated using the CR2032 coin-type cell with $\mathrm{NMOH}$ as the cathode and $\mathrm{Zn}$ foil as the anode (Fig. 3a). Figure $3 \mathrm{~b}$ shows the first three $\mathrm{CV}$ curves of the NMOH cathode performed at the scan rate of $0.1 \mathrm{mV} \mathrm{s}^{-1}$ within the voltage window of $0.8-1.9 \mathrm{~V}$ (vs. $\mathrm{Zn} / \mathrm{Zn}^{2+}$ ). In the first cathodic cycle, the peak at $1.19 \mathrm{~V}$ corresponds to the electrochemical insertion of zinc ions into the NMOH nanosheets. A broad peak centered at $1.62 \mathrm{~V}$ with a shoulder peak at $1.68 \mathrm{~V}$ can be observed in the first anodic cycle. These two peaks are mainly caused by the extraction of zinc ions and sodium ions out of the intra-gallery of $\mathrm{NMOH}$ nanosheets and the oxidation of manganese ions. After the first cycle, the two well-defined cathodic peaks at 1.24 and $1.36 \mathrm{~V}$, and the two anodic peaks at 1.57 and $1.62 \mathrm{~V}$ are nearly the same in the subsequent second and third $\mathrm{CV}$ curves, corresponding to a two-step electrochemical reaction with an excellent reversibility, consistent with the galvanostatic charge/discharge curves (Fig. S4). The rate and cycling performances of the $\mathrm{NMOH}$ cathode are measured at different current densities from 200 to $1500 \mathrm{~mA} \mathrm{~g}^{-1}$ in the aqueous electrolyte of $2 \mathrm{M}$ $\mathrm{ZnSO}_{4}$ with $0.2 \mathrm{M} \mathrm{MnSO}_{4}$. Figure $3 \mathrm{c}$ presents the galvanostatic charge/discharge curves of the $\mathrm{NMOH}$ cathode at varied current densities. The NMOH electrode exhibits excellent rate performances with average reversible capacities of $340.7,350.2,307.8,285.2,237.1,165.7,128.6,102.1$, and $87.1 \mathrm{~mA} \mathrm{~h} \mathrm{~g}^{-1}$ at current densities of 200, 300, 400, $500,600,800,1000,1200$, and $1500 \mathrm{~mA} \mathrm{~g}^{-1}$, respectively (Fig. 3d). When the current density returns to $200 \mathrm{~mA} \mathrm{~g}^{-1}$, the specific capacity of the NMOH electrode is fully recovered and even slightly higher than the initial value, indicating the excellent electrochemical performance. The $\mathrm{NMOH}$ (a)

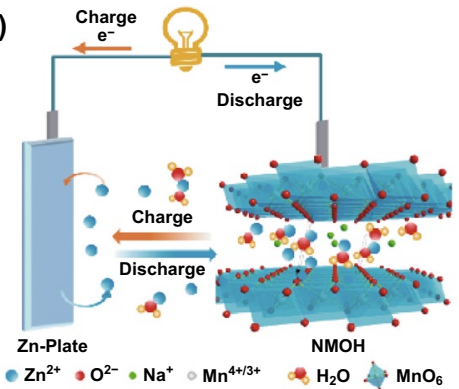

(b)

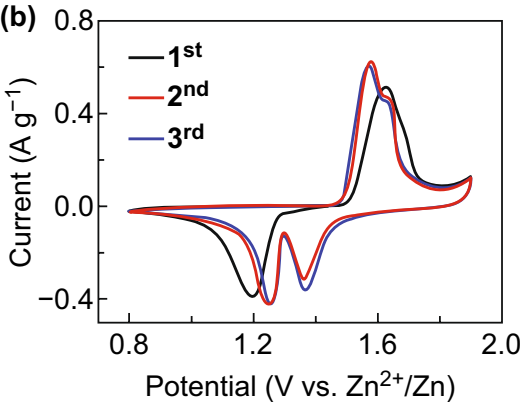

(c)

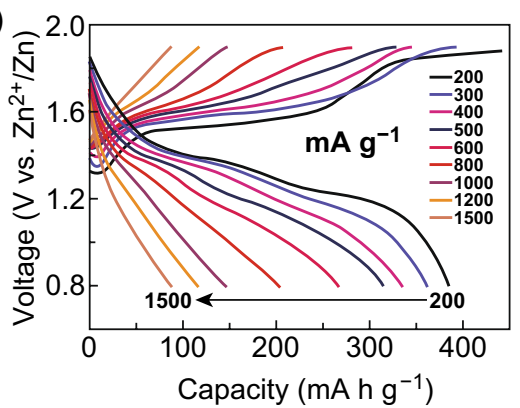

(d) $\overparen{T}$

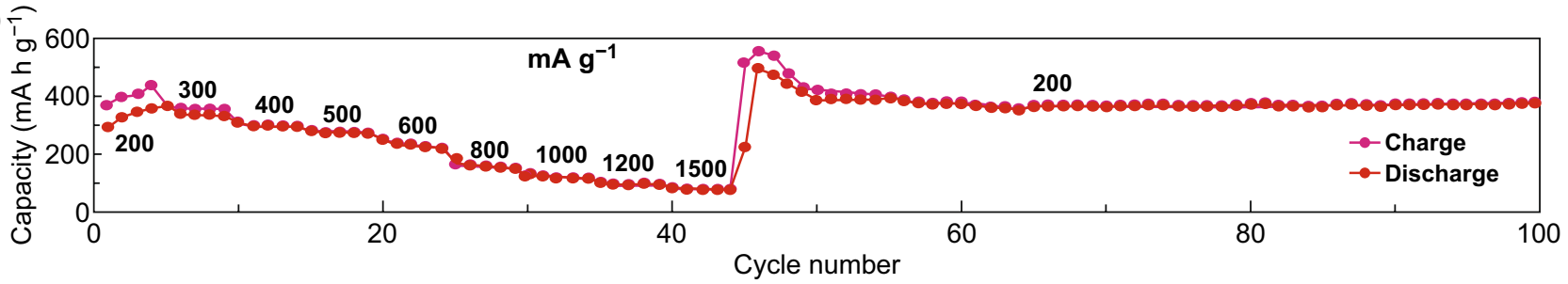

(e)

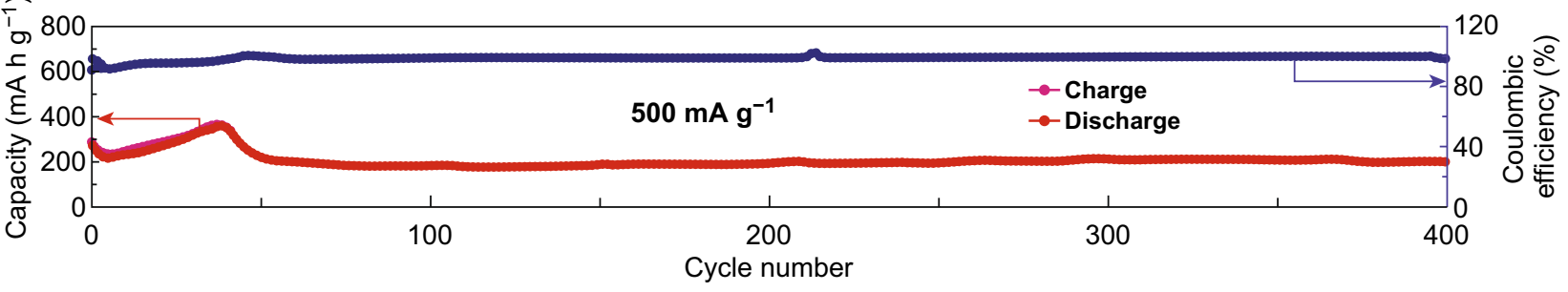

Fig. 3 Electrochemical performances of NMOH electrode. a Working principle of an aqueous ZIB with NMOH as the cathode and Zn foil as the anode. $\mathbf{b} \mathrm{CV}$ curves of coin-type $\mathrm{Zn} / \mathrm{NMOH}$ cell with the aqueous electrolyte of $2 \mathrm{M} \mathrm{ZnSO}_{4}$ and $0.2 \mathrm{M} \mathrm{MnSO}_{4}$ at a scan rate of $0.1 \mathrm{mV} \mathrm{s}^{-1}$. $\mathbf{c}$ Galvanostatic charge/discharge profiles of the $\mathrm{Zn} / \mathrm{NMOH}$ cell tested between 0.8 and $1.9 \mathrm{~V}$ with different current densities. $\mathbf{d}$ Rate performances of $\mathrm{NMOH}$ electrode at current densities between 200 and $1500 \mathrm{~mA} \mathrm{~g}^{-1}$. e Long-cycling performances of $\mathrm{NMOH}$ electrode at $500 \mathrm{~mA} \mathrm{~g}^{-1}$ 
cathode continues to conduct the cycling performance at the current density of $200 \mathrm{~mA} \mathrm{~g}^{-1}$. After 100 cycles, the specific capacity is still stable at $389.8 \mathrm{~mA} \mathrm{~h} \mathrm{~g}^{-1}$, demonstrating the good stability and reversibility of the $\mathrm{NMOH}$ cathode.

Besides, the electrochemical performances of the cointype $\mathrm{Zn} / \mathrm{NMOH}$ cell using an aqueous electrolyte of $2 \mathrm{M}$ $\mathrm{ZnSO}_{4}$ without the $0.2 \mathrm{M} \mathrm{MnSO}_{4}$ additive are also explored. The overpotential of the cell in the bare $\mathrm{ZnSO}_{4}$ electrolyte is higher than that in the $\mathrm{ZnSO}_{4}$ electrolyte with $\mathrm{MnSO}_{4}$ (Fig. S5a), and the specific capacity decreases rapidly to lower than $100 \mathrm{~mA} \mathrm{~h} \mathrm{~g}^{-1}$ just after several cycles in the electrolyte without the $\mathrm{MnSO}_{4}$ additive at the current density of $200 \mathrm{~mA} \mathrm{~g}^{-1}$ (Fig. S5b), indicating the important role of $\mathrm{MnSO}_{4}$ in the charge/discharge processes. It is quite common that the structure of Mn-based electrode materials could be destroyed during the cycling, which is caused by the dissolution of $\mathrm{Mn}^{2+}$ from $\mathrm{Mn}^{3+}$ disproportionation due to the Jahn-Teller distortion [13, 30]. In the present work, $\mathrm{MnSO}_{4}$ could prevent the dissolution of manganese from the $\mathrm{NMOH}$, resulting in a higher specific capacity. Figure S6 shows SEM image and corresponding EDS spectrum of the $\mathrm{NMOH}$ electrode after recharging to $1.9 \mathrm{~V}$. The molar ratio of $\mathrm{O} / \mathrm{Mn}(\sim 2.465)$ is nearly consistent with the original $\mathrm{O} /$ Mn state ( 2.285), revealing the excellent stability of the $\mathrm{NMOH}$ nanosheets in the presence of the $\mathrm{MnSO}_{4}$ additive. Therefore, the NMOH electrode exhibits a high Coulombic efficiency nearly up to $100 \%$ with a steady specific capacity of $201.6 \mathrm{~mA} \mathrm{~h} \mathrm{~g}^{-1}$ for at least 400 cycles at the current density of $500 \mathrm{~mA} \mathrm{~g}^{-1}$ (Fig. 3e). The corresponding charge/discharge curves at 10th, 300th, and 400th cycles show similar voltage profiles (Fig. S7), indicating the excellent stability of zinc-ion egress/ingress in the NMOH nanosheets. Besides, the obtained specific capacities of $\mathrm{NMOH}$ at varied current densities are higher than those of Mn-based aqueous ZIBs reported recently (Table S1), confirming the advantage of the layered sodium-ion/crystal water co-intercalated Birnessite cathode.

To confirm the crucial roles of $\mathrm{Na}^{+}$and crystal water, the electrochemical performances of neat $\delta-\mathrm{MnO}_{2}$ and annealed $\mathrm{NMOH}$ electrodes are also examined under the same conditions. Neat $\delta-\mathrm{MnO}_{2}$ exhibits a similar layered structure to $\mathrm{NMOH}$, but it is not stabilized with Na-ions. The layered structure is favorable for the diffusion of $\mathrm{Zn}^{2+}$, thus the $\delta-\mathrm{MnO}_{2}$ electrode could perform a high discharge capacity of $194.2 \mathrm{~mA} \mathrm{~h} \mathrm{~g}^{-1}$ at $500 \mathrm{~mA} \mathrm{~g}^{-1}$ in the second cycle, but the capacity dropped swiftly to $72.0 \mathrm{~mA} \mathrm{~h} \mathrm{~g}^{-1}$ after 40 cycles (Fig. S8), strongly supporting the crucial role of $\mathrm{Na}^{+}$in the $\mathrm{Zn}^{2+}$ storage of the novel $\mathrm{NMOH}$ cathode. To confirm the considerable role of the crystal water content in the $\mathrm{Zn}^{2+}$ storage performance, the $\mathrm{NMOH}$ samples are thermally annealed at 150 and $300{ }^{\circ} \mathrm{C}$ for $2 \mathrm{~h}$ in Ar, which are designated as NMOH-150 and NMOH-300, respectively. The content of crystal water decreases with the increasing temperature (Fig. S9a). More critically, the two NMOH samples still maintain their layered structure due to stabilization effect of the sodium ions, but the intensities of the (001) and (002) peaks evidently decrease due to the removal of crystal water after the heat treatment (Fig. S9b). Besides, the interlayer space decreases with increasing the temperature, as confirmed by the shifts of the (001) and (002) peaks (Fig. S9b). As shown in Fig. S10, the electrochemical performances become worse with the decreasing crystal water content. Clearly, both $\mathrm{Na}^{+}$and crystal water indeed play important roles in stabilizing the layered structure and enhancing the electrochemical properties of the NMOH electrode.

Interestingly, an activation process is observed in the long-term stability tests (Fig. 3e). Ex situ SEM images of the dissembled cells are used to investigate changes in surface morphologies. After the first electrochemical cycle, the surface of the electrode becomes rough (Fig. 4a), benefiting from the in situ redeposition of $\mathrm{MnO}_{x}$ derived from the dissolved manganese ions [30,51]. The wettability of the electrode increases gradually upon cycling, leading to a faster ion transport efficiency, thus improving the performances of the ZIB, which is also a vital reason for the initial activation process $[34,41]$. In addition, the formation of defects caused by the dissolution of Mn upon discharge leads to enriched active sites on the electrode surface, benefiting the improvement in the zinc-ion insert/ extract reaction kinetics $[41,52]$. The slight capacity fading after the activation process is also observed in previous studies. In the present work, the decrease in capacity may be caused by the continuous consumption of electrolyte or the impermeable passivation layer formation on the $\mathrm{Zn}$ anode [30, 31, 33, 34, 43, 52]. Additionally, the deposition of $\mathrm{Zn}_{4} \mathrm{SO}_{4}(\mathrm{OH})_{6} \cdot 0.5 \mathrm{H}_{2} \mathrm{O}$ flakes on the surface of $\mathrm{Zn}$ anode after a long cycling (Fig. S11) may reduce the ion transport rate of zinc ions and increase the interfacial impedance of the cell, thus leading to the fading process. Then, a relative high reversible capacity could be maintained at $201.6 \mathrm{~mA} \mathrm{~h} \mathrm{~g}^{-1}$ for the subsequent cycles. 

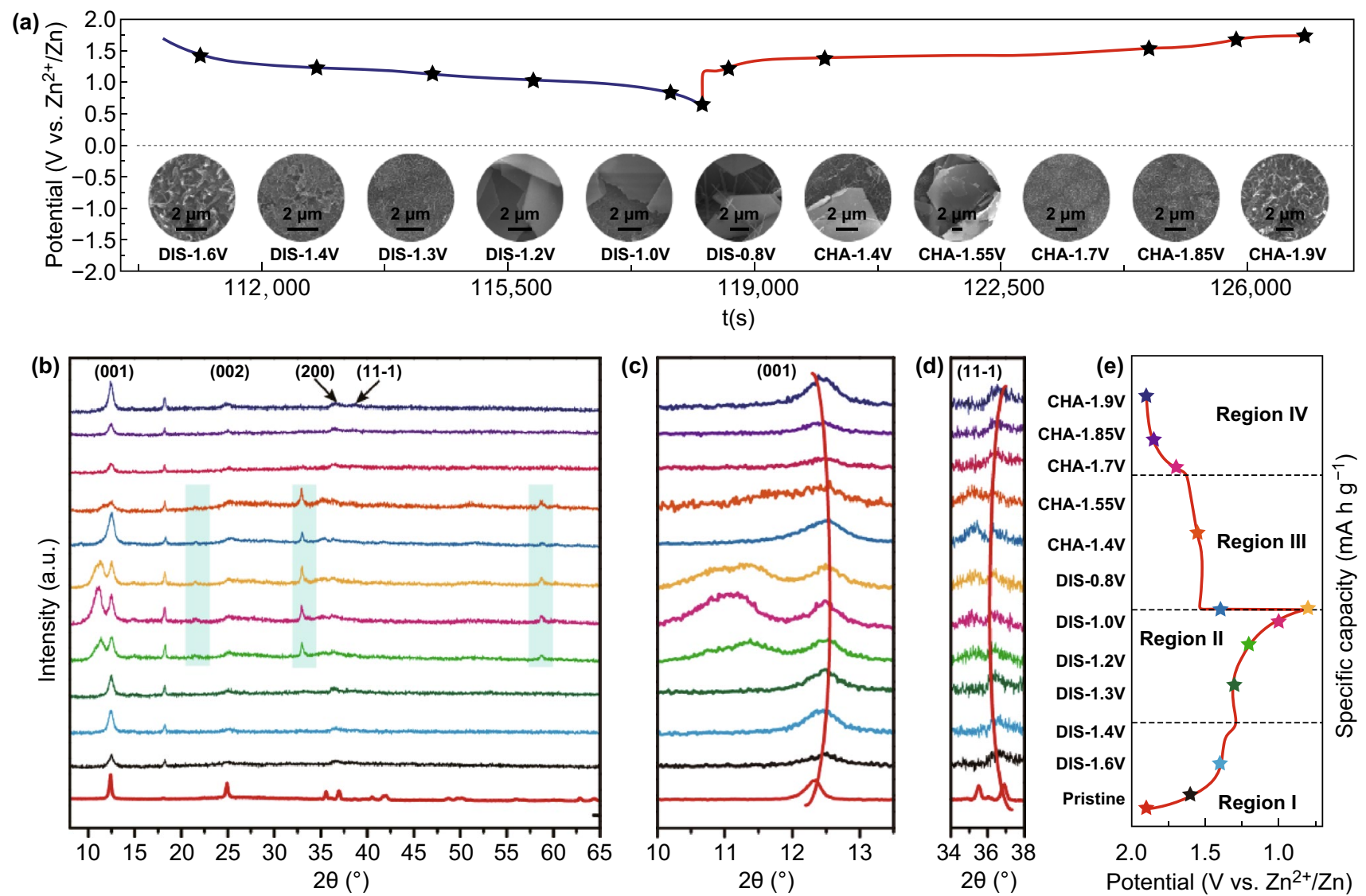

Fig. 4 a Typical charge/discharge profile and corresponding SEM images of NMOH cathode in the second cycle. b-e Ex situ XRD patterns at different charge/discharge states and corresponding GCD curves of NMOH cathode at the current density of $200 \mathrm{~mA} \mathrm{~g}^{-1}$ in the second cycle

The reaction mechanism of zinc-ion storage is further evaluated using ex situ XRD, SEM, EDS, and XPS at various discharge/charge states during the second cycle within the potential window of $0.8-1.9 \mathrm{~V}$ at $200 \mathrm{~mA} \mathrm{~g}^{-1}$, and the corresponding discharge/charge states are marked in the charge/discharge profile (Fig. 4e). As depicted in Fig. 4b, the ex situ XRD patterns demonstrate the peak changes of the NMOH electrode. The prominent diffraction peaks of $\mathrm{NMOH}$ are observed at different discharge and charge states, indicating that the layered structure of $\mathrm{NMOH}$ is retained during the zinc-ion insertion/extraction processes. In detail, during the discharging process, the peak of (001) shifts gradually from $12.3^{\circ}$ toward a higher angle (Fig. 4c), while the peak of (11-1) shifts toward a lower angle (Fig. 4d). The peak shifts of (001) imply a reduction in the interlayer distance of the NMOH during the discharge process (Fig. 4c), because of the strong electrostatic interaction between the $\mathrm{MnO}_{6}$ octahedral sheets and the intercalated zinc ions [20,
43]. The peak shifts of (11-1) demonstrate an increase in the inter-planar distance during the discharge process (Fig. 4d), which is caused by the expansion of the $\mathrm{Mn}-\mathrm{O}$ bonds upon $\mathrm{Mn}^{4+} / \mathrm{Mn}^{3+}$ and $\mathrm{Mn}^{4+} / \mathrm{Mn}^{2+}$ reductions [43], since the bond lengths of the $\mathrm{Mn}^{2+}-\mathrm{O}$ and $\mathrm{Mn}^{3+}-\mathrm{O}$ are longer than that of $\mathrm{Mn}^{4+}-\mathrm{O}$ [53]. Interestingly, the (001) and (11-1) peaks could return to their original positions after the charging reaction, implying that the intercalation/deintercalation of zinc ions is a reversible process without the destruction of the $\mathrm{NMOH}$.

Further analyses of the ex situ XRD show that no new significant diffraction peaks appear at the Region I (the first discharge platform, Fig. 4e), while multiple new peaks emerge at the Region II (the second discharge platform, Fig. 4e). The peak, which appears at $10.5^{\circ}$ and disappears at the beginning of charging, might be assigned to the extra water layer, due to the solvation effect in the form of the water shell around the zinc ions during the discharging process. As reported, the water shell around the zinc ions could reduce the 
electrostatic interaction between the zinc ions and the $\mathrm{MnO}_{6}$ octahedral sheets to increase the ion transport rate $[18,19$, $38]$. Besides, the emerging peaks at $21.5^{\circ}, 32.9^{\circ}$, and $58.7^{\circ}$ in the Region II correspond to the new phase of zinc sulfate hydroxide hydrate $\left(\mathrm{Zn}_{4} \mathrm{SO}_{4}(\mathrm{OH})_{6} \cdot 0.5 \mathrm{H}_{2} \mathrm{O}\right.$, JCPDS No. 44-0674) [31, 32, 54-57]. Furthermore, a set of tiny peaks at $12.4^{\circ}, 25.1^{\circ}, 35.1^{\circ}$, and $41.6^{\circ}$ of $\mathrm{Zn}_{4} \mathrm{SO}_{4}(\mathrm{OH})_{6} \cdot 0.5 \mathrm{H}_{2} \mathrm{O}$ are observed after discharging to $0.8 \mathrm{~V}$. No other phases, such as $\mathrm{ZnO}, \mathrm{Mn}_{2} \mathrm{O}_{3}$, and $\mathrm{MnOOH}$, are present during the discharge/ charge processes, confirming the structural stability of the NMOH (Fig. S12). The formation of zinc sulfate hydroxide hydrate is attributed to the increased amount of $\mathrm{OH}^{-}$in the electrolyte due to the insertion of $\mathrm{H}^{+}$to the electrode in the first discharge platform [13, 24, 31]. In subsequent charging process, these new peaks decrease gradually and completely disappear at the end of the charging process, indicating the reversibility of the new phase of $\mathrm{Zn}_{4} \mathrm{SO}_{4}(\mathrm{OH})_{6} \cdot 0.5 \mathrm{H}_{2} \mathrm{O}$.

The surface morphology evolution of the electrode is studied using ex situ SEM images (Fig. 4a). In the early stage of the discharge process, no significant morphology transformation except for the increase in surface roughness was observed. However, after discharging to $1.2 \mathrm{~V}$, the flakes with length and width of several micrometers are generated and maintained stably on the surface of the electrode until their disappearance after recharging to $1.55 \mathrm{~V}$. Simultaneously, the surface morphology of the $\mathrm{NMOH}$ electrode remains stable without significant changes. Such a phenomenon is consistent with the XRD results. The EDS mapping images show the uniform distribution of $\mathrm{Na}, \mathrm{Zn}, \mathrm{O}$, and $\mathrm{S}$ elements within the surface of the sample (Fig. S13), further confirming the microflakes to be zinc sulfate hydroxide hydrate. The presented sodium ions are de-intercalated along with the zinc ions upon charging during the first electrochemical cycle and then adsorbed on the surface of the microflakes during the discharge process.

To understand the electrode reaction mechanism definitely, the chemical states of the NMOH nanosheets during charge/discharge processes have been characterized (Fig. 5). As illustrated in Fig. 5a, no signal of Zn $2 p$ could be detected in the initial state of the $\mathrm{NMOH}$ electrode, whereas four peaks are observed after discharge to $0.8 \mathrm{~V}$, demonstrating the insertion of zinc ions into $\mathrm{NMOH}$ nanosheets with different coordinations. After recharge to $1.9 \mathrm{~V}$, two peaks disappear, while the intensities of the other two peaks of $\mathrm{Zn} 2 p$ are far below the fully discharged states, confirming that most of zinc ions are extracted from the electrode [20,
30, 31]. Based on the discussion in Fig. 4, the appearance/ disappearance of the two peaks at 1023.6 and $1046.8 \mathrm{eV}$ should be ascribed to the reversible formation of zinc sulfate hydroxide hydrate, which is the solid proof for the intercalation of $\mathrm{H}^{+}$into the $\mathrm{NMOH}$, while the other two peaks at 1021.5 and $1044.6 \mathrm{eV}$ are attributed to the intercalation of zinc ions to the NMOH. In particular, the small number of trapped $\mathrm{Zn}$ ions in the electrode might serve as the interlayer pillars to further stabilize the layered structure of $\mathrm{NMOH}$ upon electrochemical cycles.

As demonstrated above, both $\mathrm{H}^{+}$and $\mathrm{Zn}^{2+}$ could insert into the cathode upon discharge, corresponding to a twostep process. Figure S14 shows the EDS patterns of the $\mathrm{NMOH}$ electrode and the $\mathrm{Zn} / \mathrm{Mn}$ molar ratio at different statuses during the second cycle at $200 \mathrm{~mA} \mathrm{~g}^{-1}$. Some $\mathrm{Zn}^{2+}$ could be seen in the fully charged cathode with the $\mathrm{Zn} / \mathrm{Mn}$ molar ratio of 0.13 , further certificating the small number of trapped zinc ions in the electrode (Fig. S14a). At the end of the first discharge platform (discharged to $1.3 \mathrm{~V}$ ), the ratio of $\mathrm{Zn} / \mathrm{Mn}$ changes to 0.36 , indicating that a low quantity of zinc ions insert into the NMOH nanosheets (Fig. S14b). Furthermore, the $\mathrm{Zn} / \mathrm{Mn}$ ratio increases from 0.36 to 1.05 in the fully charged electrode, proving that the insertion of $\mathrm{Zn}^{2+}$ dominates the second discharge process (Fig. S14c). Besides, the ion diffusion coefficients (D) in the first discharge platform (platform I, point 1) and the second discharge platform (platform II, point 2) are investigated with EIS measurements to distinguish the different parts of the discharge platforms (Fig. S15). The calculated ion diffusion coefficient at point $1\left(1.36 \times 10^{-12} \mathrm{~cm}^{2} \mathrm{~s}^{-1}\right)$ is much larger than that in the point $2\left(2.64 \times 10^{-14} \mathrm{~cm}^{2} \mathrm{~s}^{-1}\right)$, suggesting that the discharge platforms I and II are essentially ascribed to the insertion of $\mathrm{H}^{+}$and $\mathrm{Zn}^{2+}$, respectively, due to the tinier size and electrostatic repulsion of $\mathrm{H}^{+}$than $\mathrm{Zn}^{2+}[32,54]$.

The Mn valence states of the $\mathrm{NMOH}$ electrode at different statuses during the discharge/charge processes are shown in Fig. 5b. Different from the pristine sample, the intensities of $\mathrm{Mn}^{3+}$ peaks increase after discharged to $0.8 \mathrm{~V}$ and $\mathrm{Mn}^{2+}$ could be detected, further implying the intercalation of zinc ions into the NMOH sheets and the reduction of $\mathrm{Mn}^{4+}$ [15]. In the extraction state, the peak area of $\mathrm{Mn}^{4+}$ increases, revealing that most $\mathrm{Mn}^{3+} / \mathrm{Mn}^{2+}$ are reoxidized owing to the extraction of $\mathrm{Zn}^{2+}$ from the cathode material [15]. However, the signal of $\mathrm{Mn}^{2+}$ does not completely disappear, due to the trapped $\mathrm{Zn}^{2+}$ in the electrode. The changes of manganese oxidation state are also characterized by the $\mathrm{O} 1 s$ core-level 

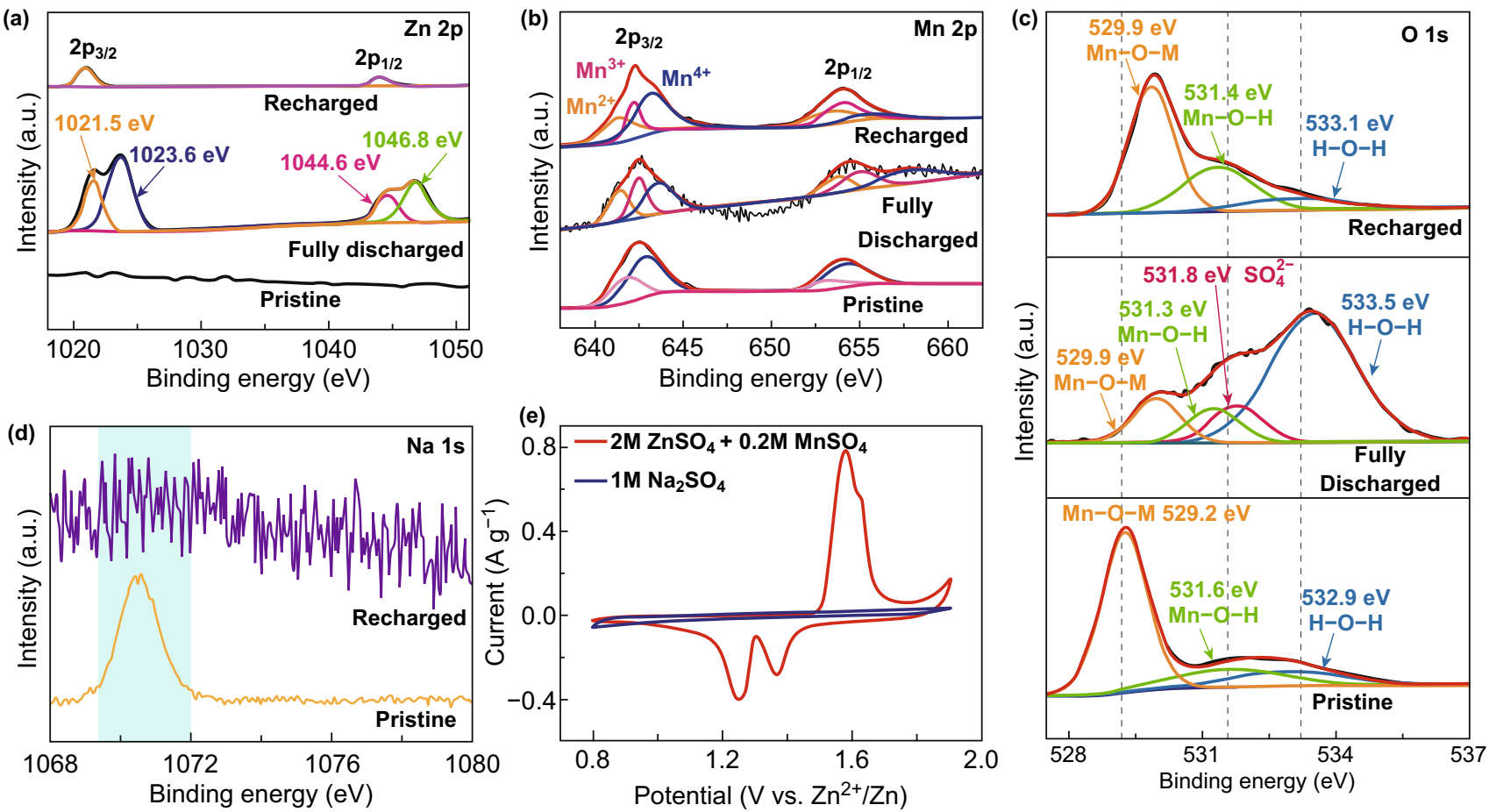

Fig. 5 High-resolution XPS spectra of a Zn $2 p, \mathbf{b}$ Mn $2 p$, and $\mathbf{c} \mathrm{O} 1 s$ at initial, fully discharged, and charged statuses. d XPS Na $1 s$ spectra at different statuses of initial and after recharged to $1.9 \mathrm{~V}$. e Cyclic voltammetry curves of the coin-type $\mathrm{Zn} / \mathrm{NMOH}$ cell at $0.1 \mathrm{mV} \mathrm{s}^{-1}$ using aqueous electrolytes of $2 \mathrm{M} \mathrm{ZnSO}_{4}+0.2 \mathrm{M} \mathrm{MnSO}_{4}$ (red) and $1 \mathrm{M} \mathrm{Na}_{2} \mathrm{SO}_{4}$ (blue). (Color figure online)

spectra (Fig. 5c). In addition to the three peaks of Mn-O-M, $\mathrm{Mn}-\mathrm{O}-\mathrm{H}$ and $\mathrm{H}-\mathrm{O}-\mathrm{H}$ in the insertion state, a new peak at $531.8 \mathrm{eV}$ could be assigned to $\mathrm{SO}_{4}{ }^{2-}$ derived from the new phase of $\mathrm{Zn}_{4} \mathrm{SO}_{4}(\mathrm{OH})_{6} \cdot 0.5 \mathrm{H}_{2} \mathrm{O}$ [24, 44]. The intensity of $\mathrm{H}-\mathrm{O}-\mathrm{H}$ peak increases obviously owing to the intercalation of water into the $\mathrm{NMOH}$ nanosheets in the form of the water shell around zinc ions. The water molecules are wrapped around the zinc ions, helping reduce the electrostatic effect as well as promoting the transport of zinc ions between the $\mathrm{NMOH}$ layers. Furthermore, when the cell recharged to $1.9 \mathrm{~V}$, the peak of $\mathrm{SO}_{4}{ }^{2-}$ disappears while the intensity of $\mathrm{H}-\mathrm{O}-\mathrm{H}$ peak decreases, which is ascribed to the dissolution of $\mathrm{Zn}_{4} \mathrm{SO}_{4}(\mathrm{OH})_{6} \cdot 0.5 \mathrm{H}_{2} \mathrm{O}$ and the extraction of $\mathrm{H}_{2} \mathrm{O}$. In addition, the peak of Mn-O-M at $529.2 \mathrm{eV}$ moves to a higher binding energy because of the insertion of zinc ions.

Sodium ions also play an important role in the electrochemical process of the $\mathrm{NMOH}$ electrode. As shown in Fig. S16, when sodium ions are extracted from the $\mathrm{NMOH}$ electrode at first, the electrochemical performance of the electrode is far worse than the electrode that has experienced the discharge process at first, indicating that sodium ions support the $\mathrm{NMOH}$ layer for promoting the insertion and transport of zinc ions in the first discharge process. When the cell undergoes discharge process at first, only a broad peak of $\mathrm{Na} 1 s$ could be detected at fully charged state, implying that only a small amount of sodium ions is present in the electrode material (Fig. 5d). Moreover, the results of ICP-AES show that the concentration of sodium ions in the electrolyte increases significantly at the fully charged state (Table S2), meaning that numerous sodium ions are extracted from the electrode during the charging process in the first cycle. Besides, the trapped zinc ions replace sodium ions to form a new phase of $\mathrm{Zn}_{0.13} \mathrm{Na}_{x} \mathrm{Mn}_{2} \mathrm{O}_{4} \cdot n \mathrm{H}_{2} \mathrm{O}$, where the concentration of zinc ions is determined by EDS in Fig. S14. The trapped zinc ions could also serve as the pillar to support the interlayers for subsequent cycles. Such an electrochemical reaction of the $\mathrm{NMOH}$ could be classified as the displacement/intercalation reaction mechanism proposed firstly in the current Mn-based cathodes, similar to the reported V-based cathodes $[20,58]$. The whole process could be described as follows: During the first cycle, sodium ions act as a pillar for the intercalation of zinc ions upon discharge, because the ionic radius of sodium ions $(1.02 \AA)$ is much larger than that of zinc ions $(0.74 \AA)$ [18]; 
furthermore, the zinc ions replace part of sodium ions to stabilize the interlayers of the $\mathrm{NMOH}$, preventing the electrode from collapse and enhancing the performance of the cell during the following discharge/charge process.

Sodium ions not only play a crucial role in cyclic performances of the NMOH cathode, but also contribute to the capacities of the cell. As shown in Figs. 5e and S17, the coin-type $\mathrm{Zn} / \mathrm{NMOH}$ cell with $1 \mathrm{M} \mathrm{NaSO}_{4}$ as the electrolyte delivers a little capacity, because the sodium ions adsorbed on the cathode surface generate the pseudo-capacitance upon discharge [35, 59-61]. The elemental mapping images confirm the presence of adsorbed sodium ions (Fig. S13). The adsorption/desorption mechanism of sodium ions discussed above is consistent with the reported [59]. The concentration of sodium ions in $\mathrm{Zn} / \mathrm{NMOH}\left(2 \mathrm{M} \mathrm{ZnSO}_{4}+0.2 \mathrm{M} \mathrm{MnSO}_{4}\right)$ is far below $1 \mathrm{~mol} \mathrm{~L}^{-1}$, and the sodium ions would donate a little capacity for the cell; however, the role of sodium ions is irreplaceable in enhancing the performance of the ZIBs.

Figure 6 depicts the electrochemical mechanism. In the first discharge process, the solvation zinc ions intercalate into the layered $\mathrm{NMOH}$ electrode to replace part of sodium ions that serve as a pillar to support the layered structure, followed by the deintercalation of $\mathrm{Zn}^{2+} / \mathrm{Na}^{+}$from the $\mathrm{NMOH}$ electrode during the first charge process. In the subsequent discharge process, $\mathrm{H}^{+}$insert into the $\mathrm{NMOH}$ electrode in the first platform along with the formation of the new phase of $\mathrm{Zn}_{4} \mathrm{SO}_{4}(\mathrm{OH})_{6} \cdot 0.5 \mathrm{H}_{2} \mathrm{O}$, and then, $\mathrm{Zn}^{2+}$ insert into the $\mathrm{NMOH}$ electrode in the second platform to form the new phase of $\mathrm{Zn}$-inserted phase; meanwhile, sodium ions are adsorbed on the surface to generate a little pseudo-capacitance. In the following charge process, $\mathrm{Zn}^{2+} / \mathrm{H}^{+}$could extract reversibly from the electrode accompanied by desorption of sodium ions. Such a displacement/intercalation reaction mechanism endows the $\mathrm{NMOH}$ electrode with a high reversible capacity and a satisfactory cyclability.

\section{Conclusions}

A layered sodium-ion/crystal water co-intercalated $\mathrm{Na}_{0.55} \mathrm{Mn}_{2} \mathrm{O}_{4} \cdot 0.57 \mathrm{H}_{2} \mathrm{O}$ was synthesized by the rearrangement of $\mathrm{MnO}_{6}$ octahedrons with sodium ions and water molecules via selectively etching the silica tetrahedrons of manganese silicate with $\mathrm{NaOH}$ solution. The as-synthesized $\mathrm{NMOH}$ with numerous mesopores and active sites is used as the high-performance cathode of ZIBs for the first time. On the basis of the ex situ XPS, XRD, EDS, ICP-AES,
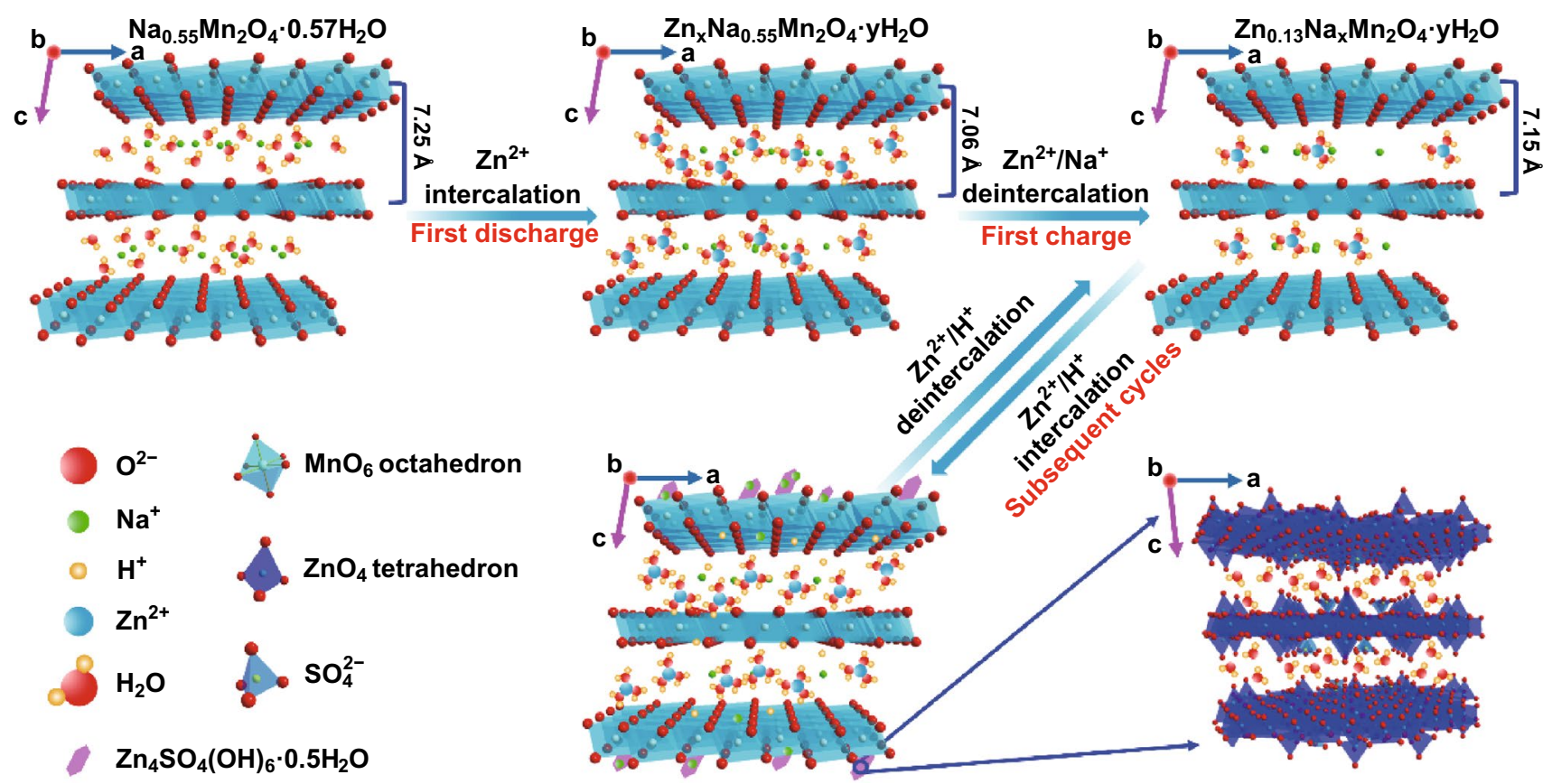

First charge
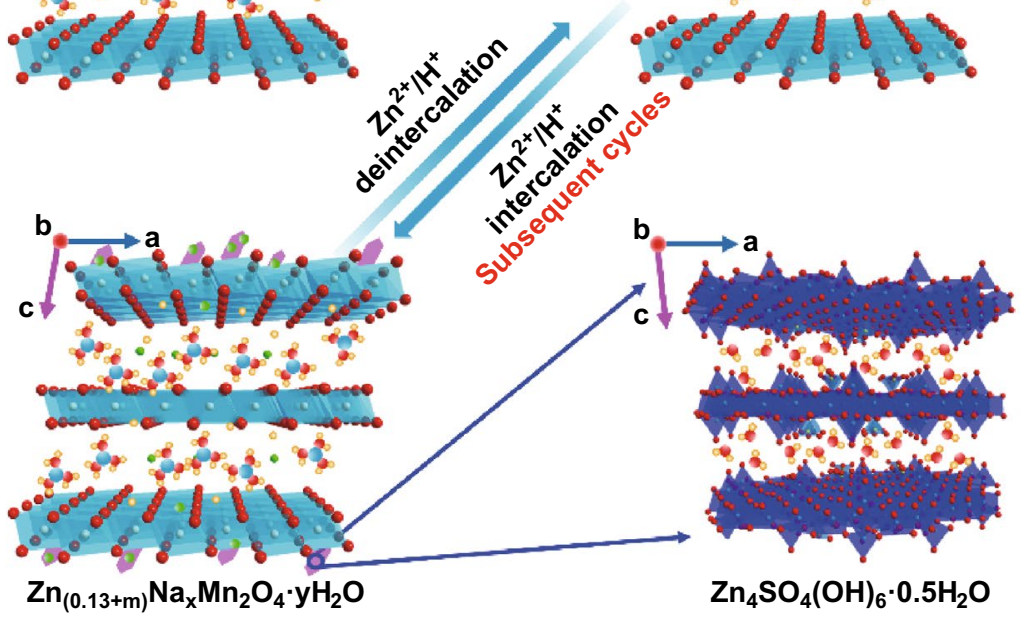

Fig. 6 Schematic illustration of the displacement/intercalation reaction mechanism in the first cycle, and the insertion/extraction mechanism of zinc ions in subsequent electrochemical discharge/charge processes 
and SEM results, a displacement/intercalation mechanism is firstly confirmed in the Mn-based cathode of ZIBs. In a word, the sodium-ion/crystal water co-intercalated $\mathrm{NMOH}$ with a large interlayer spacing enables the insertion of zinc ions during the first discharge process, and then a small number of zinc ions replace the sodium ions to improve the stability of the layered structure during the consecutive electrochemical reactions. The reversible insertion/extraction of $\mathrm{Zn}^{2+} / \mathrm{H}^{+}$into/out of the $\mathrm{NMOH}$ is accompanied with the adsorption/desorption of $\mathrm{Na}^{+}$and the reversible formation of $\mathrm{Zn}_{4} \mathrm{SO}_{4}(\mathrm{OH})_{6} \cdot 0.5 \mathrm{H}_{2} \mathrm{O}$ during the subsequent discharge/ charge cycles. The $\mathrm{Na}_{0.55} \mathrm{Mn}_{2} \mathrm{O}_{4} \cdot 0.57 \mathrm{H}_{2} \mathrm{O}$ nanosheets show a high reversible capacity of $389.8 \mathrm{~mA} \mathrm{~h} \mathrm{~g}^{-1}$ at a current density of $200 \mathrm{~mA} \mathrm{~g}^{-1}$, and an excellent cyclability with a high capacity of $201.6 \mathrm{~mA} \mathrm{~h} \mathrm{~g}^{-1}$ at $500 \mathrm{~mA} \mathrm{~g}^{-1}$ after 400 cycles. Therefore, alkali metal ions and crystal water as the pillar of the Mn-based cathode are effective in stabilizing the crystal structure and improving the transport of zinc ions for high-performance ZIBs.

Acknowledgements Financial support from the National Natural Science Foundation of China (51972016, 51533001), the National Key Research and Development Program of China (2016YFC0801302), and State Key Laboratory of Organic-Inorganic Composites (oic-201801002) is gratefully acknowledged.

Supporting Information XRD pattern of $\mathrm{Mn}_{x} \mathrm{Si}_{y} \mathrm{O}_{z}$ and $\delta-\mathrm{MnO}_{2}$; TG analysis, SEM, and the adsorption isotherm of NMOH; electrochemical characterization of the cell $(\mathrm{Zn} / \mathrm{NMOH})$; SEM and corresponding EDS spectra of the NMOH electrode; electrochemical performances of $\mathrm{NMOH}$ with different annealing temperatures; comparison of electrochemical properties of $\mathrm{NMOH}$ with previously reported Mn-based cathode materials; SEM images of Zn anode at different states; calculated diffusion coefficients of different discharge platforms. The ex situ XRD patterns; the GCD curves and cycling performance with different charging and discharging methods; ICP-AES results of the $\mathrm{Na}^{+}$.

Open Access This article is licensed under a Creative Commons Attribution 4.0 International License, which permits use, sharing, adaptation, distribution and reproduction in any medium or format, as long as you give appropriate credit to the original author(s) and the source, provide a link to the Creative Commons licence, and indicate if changes were made. The images or other third party material in this article are included in the article's Creative Commons licence, unless indicated otherwise in a credit line to the material. If material is not included in the article's Creative Commons licence and your intended use is not permitted by statutory regulation or exceeds the permitted use, you will need to obtain permission directly from the copyright holder. To view a copy of this licence, visit http://creativecommons.org/licenses/by/4.0/.
Electronic supplementary material The online version of this article (https://doi.org/10.1007/s40820-020-0397-3) contains supplementary material, which is available to authorized users.

\section{References}

1. D. Kundu, B.D. Adams, V. Duffort, S.H. Vajargah, L.F. Nazar, A high-capacity and long-life aqueous rechargeable zinc battery using a metal oxide intercalation cathode. Nat. Energy 1(10), 16119 (2016). https://doi.org/10.1038/nener gy.2016.119

2. M. Armand, J.M. Tarascon, Building better batteries. Nature 451, 652-657 (2008). https://doi.org/10.1038/451652a

3. C.-X. Gui, S.-M. Hao, Y. Liu, J. Qu, C. Yang, Y. Yu, Q.-Q. Wang, Z.-Z. Yu, Carbon nanotube@layered nickel silicate coaxial nanocables as excellent anode materials for lithium and sodium storage. J. Mater. Chem. A 3(32), 16551-16559 (2015). https://doi.org/10.1039/c5ta03408f

4. H. Ye, Z.-J. Zheng, H.-R. Yao, S.-C. Liu, T.-T. Zuo et al., Guiding uniform Li plating/stripping through lithiumaluminum alloying medium for long-life Li metal batteries. Nano Energy 58(4), 1094-1099 (2019). https://doi. org/10.1002/anie.201811955

5. L.H. Zhang, T. Wei, Z.M. Jiang, C.Q. Liu, H. Jiang et al., Electrostatic interaction in electrospun nanofibers: doublelayer carbon protection of $\mathrm{CoFe}_{2} \mathrm{O}_{4}$ nanosheets enabling ultralong-life and ultrahigh-rate lithium ion storage. Nano Energy 48, 238-247 (2018). https://doi.org/10.1016/j.nanoe n.2018.03.053

6. W.-H. Li, Q.-L. Ning, X.-T. Xi, B.-H. Hou, J.-Z. Guo, Y. Yang, B. Chen, X.-L. Wu, Highly improved cycling stability of anion de-/intercalation in the graphite cathode for dual-ion batteries. Adv. Mater. 31(4), 1804766 (2019). https://doi.org/10.1002/ adma.201804766

7. Y.-Q. Jing, J. Qu, W. Chang, Q.-Y. Ji, H.-J. Liu, T.-T. Zhang, Z.-Z. Yu, Cobalt hydroxide carbonate/reduced graphene oxide anodes enabled by a confined step-by-step electrochemical catalytic conversion process for high lithium storage capacity and excellent cyclability with a low variance coefficient. ACS Appl. Mater. Interfaces. 11(36), 33091-33101 (2019). https:// doi.org/10.1021/acsami.9b12088

8. W. Chang, J. Qu, S.-M. Hao, Y.-J. Zhang, Z.-G. Jiang, Z.-Z. $\mathrm{Yu}$, Effects of graphene quality on lithium storage performances of $\mathrm{Fe}_{3} \mathrm{O}_{4}$ /thermally reduced graphene oxide hybrid anodes. ChemElectroChem 6(6), 1853-1860 (2019). https:// doi.org/10.1002/celc.201900015

9. W. Li, J.R. Dahn, D.S. Wainwright, Rechargeable lithium batteries with aqueous electrolytes. Science 264(5162), 11151118 (1994). https://doi.org/10.1126/science.264.5162.1115

10. M. Pasta, C.D. Wessells, R.A. Huggins, Y. Cui, A high-rate and long cycle life aqueous electrolyte battery for grid-scale energy storage. Nat. Commun. 3, 1149 (2012). https://doi. org/10.1038/ncomms 2139 
11. Y. Wang, L. Mu, J. Liu, Z. Yang, X. Yu et al., A novel high capacity positive electrode material with tunnel-type structure for aqueous sodium-ion batteries. Adv. Energy Mater. 5(22), 1501005 (2015). https://doi.org/10.1002/aenm.201501005

12. M. Song, H. Tan, D. Chao, H.J. Fan, Recent advances in zn-ion batteries. Adv. Funct. Mater. 28(41), 1802564 (2018). https:// doi.org/10.1002/adfm.201802564

13. H. Pan, Y. Shao, P. Yan, Y. Cheng, K.S. Han et al., Reversible aqueous zinc/manganese oxide energy storage from conversion reactions. Nat. Energy 1(5), 16039 (2016). https://doi. org/10.1038/nenergy.2016.39

14. N. Zhang, F. Cheng, Y. Liu, Q. Zhao, K. Lei, C. Chen, X. Liu, J. Chen, Cation-deficient spinel $\mathrm{ZnMn}_{2} \mathrm{O}_{4}$ cathode in $\mathrm{Zn}\left(\mathrm{CF}_{3} \mathrm{SO}_{3}\right)_{2}$ electrolyte for rechargeable aqueous $\mathrm{Zn}$-ion battery. J. Am. Chem. Soc. 138(39), 12894-12901 (2016). https://doi.org/10.1021/jacs.6b05958

15. Y. Fu, Q. Wei, G. Zhang, X. Wang, J. Zhang et al., Highperformance reversible aqueous $\mathrm{Zn}$-ion battery based on porous $\mathrm{MnO}_{x}$ nanorods coated by MOF-derived N-doped carbon. Adv. Energy Mater. 8(26), 1801445 (2018). https:// doi.org/10.1002/aenm.201801445

16. K. Lu, B. Song, Y. Zhang, H. Ma, J. Zhang, Encapsulation of Zinc hexacyanoferrate nanocubes with manganese oxide nanosheets for high-performance rechargeable zinc ion batteries. J. Mater. Chem. A 5(45), 23628-23633 (2017). https ://doi.org/10.1039/c7ta07834j

17. L. Zhang, L. Chen, X. Zhou, Z. Liu, Towards high-voltage aqueous metal-ion batteries beyond $1.5 \mathrm{~V}$ : the zinc/zinc hexacyanoferrate system. Adv. Energy Mater. 5(2), 1400930 (2015). https://doi.org/10.1002/aenm.201400930

18. P. He, M. Yan, G. Zhang, R. Sun, L. Chen, Q. An, L. Mai, Layered $\mathrm{VS}_{2}$ nanosheet-based aqueous $\mathrm{Zn}$ ion battery cathode. Adv. Energy Mater. 7(11), 1601920 (2017). https://doi. org/10.1002/aenm.201601920

19. Q. Pang, C. Sun, Y. Yu, K. Zhao, Z. Zhang et al., $\mathrm{H}_{2} \mathrm{~V}_{3} \mathrm{O}_{8}$ nanowire/graphene electrodes for aqueous rechargeable zinc ion batteries with high rate capability and large capacity. Adv. Energy Mater. 8(19), 1800144 (2018). https://doi. org/10.1002/aenm.201800144

20. F. Ming, H. Liang, Y. Lei, S. Kandambeth, M. Eddaoudi, H.N. Alshareef, Layered $\mathrm{Mg}_{x} \mathrm{~V}_{2} \mathrm{O}_{5} \cdot \mathrm{nH}_{2} \mathrm{O}$ as cathode material for high-performance aqueous zinc ion batteries. ACS Energy Lett. 3(10), 2602-2609 (2018). https://doi. org/10.1021/acsenergylett.8b01423

21. J. Wang, J.-G. Wang, H. Liu, C. Wei, F. Kang, Zinc ion stabilized $\mathrm{MnO}_{2}$ nanospheres for high capacity and long lifespan aqueous zinc-ion batteries. J. Mater. Chem. A 7(22), 13727-13735 (2019). https://doi.org/10.1039/C9TA03541A

22. B. Wu, G. Zhang, M. Yan, T. Xiong, P. He, L. He, X. Xu, L. Mai, Graphene scroll-coated alpha- $\mathrm{MnO}_{2}$ nanowires as high-performance cathode materials for aqueous $\mathrm{Zn}$-ion battery. Small 14(13), 1703850 (2018). https://doi.org/10.1002/ smll.201703850

23. W. Qiu, Y. Li, A. You, Z. Zhang, G. Li, X. Lu, Y. Tong, High-performance flexible quasi-solid-state $\mathrm{Zn}-\mathrm{MnO}_{2}$ battery based on $\mathrm{MnO}_{2}$ nanorod arrays coated 3D porous nitrogen-doped carbon cloth. J. Mater. Chem. A 5(28), 14838-14846 (2017). https://doi.org/10.1039/c7ta03274a

24. S. Islam, M.H. Alfaruqi, V. Mathew, J. Song, S. Kim et al., Facile synthesis and the exploration of the zinc storage mechanism of $\beta-\mathrm{MnO}_{2}$ nanorods with exposed (101) planes as a novel cathode material for high performance eco-friendly zinc-ion batteries. J. Mater. Chem. A 5(44), 23299-23309 (2017). https://doi.org/10.1039/c7ta07170a

25. M.H. Alfaruqi, V. Mathew, J. Gim, S. Kim, J. Song, J.P. Baboo, S.H. Choi, J. Kim, Electrochemically induced structural transformation in a $\gamma-\mathrm{MnO}_{2}$ cathode of a high capacity zinc-ion battery system. Chem. Mater. 27(10), 3609-3620 (2015). https://doi.org/10.1021/cm504717p

26. J. Lee, J.B. Ju, W.I. Cho, B.W. Cho, S.H. Oh, Todorokitetype $\mathrm{MnO}_{2}$ as a zinc-ion intercalating material. Electrochim. Acta 112, 138-143 (2013). https://doi.org/10.1016/j.elect acta.2013.08.136

27. C. Yuan, Y. Zhang, Y. Pan, X. Liu, G. Wang, D. Cao, Investigation of the intercalation of polyvalent Cations $\left(\mathrm{Mg}^{2+}, \mathrm{Zn}^{2+}\right)$ into $\lambda-\mathrm{MnO}_{2}$ for rechargeable aqueous battery. Electrochim. Acta 116, 404-412 (2014). https://doi.org/10.1016/j.elect acta.2013.11.090

28. W. Sun, F. Wang, S. Hou, C. Yang, X. Fan et al., Zn/ $\mathrm{MnO}_{2}$ battery chemistry with $\mathrm{H}^{+}$and $\mathrm{Zn}^{2+}$ coinsertion. J. Am. Chem. Soc. 139(29), 9775-9778 (2017). https://doi.org/10.1021/ jacs.7b04471

29. H. Zhang, J. Wang, Q. Liu, W. He, Z. Lai et al., Extracting oxygen anions from $\mathrm{ZnMn}_{2} \mathrm{O}_{4}$ : robust cathode for flexible all-solid-state Zn-ion batteries. Energy Storage Mater. 21, 154-161 (2019). https://doi.org/10.1016/j.ensm.2018.12.019

30. X. Wu, Y. Xiang, Q. Peng, X. Wu, Y. Li et al., Green-low-cost rechargeable aqueous zinc-ion batteries using hollow porous spinel $\mathrm{ZnMn}_{2} \mathrm{O}_{4}$ as the cathode material. J. Mater. Chem. A. 5(34), 17990-17997 (2017). https://doi.org/10.1039/c7ta0 $0100 b$

31. V. Soundharrajan, B. Sambandam, S. Kim, V. Mathew, J. Jo et al., Aqueous magnesium zinc hybrid battery: an advanced high-voltage and high-energy $\mathrm{MgMn}_{2} \mathrm{O}_{4}$ cathode. ACS Energy Lett. 3(8), 1998-2004 (2018). https://doi.org/10.1021/acsen ergylett. $8 \mathrm{~b} 01105$

32. C. Guo, H. Liu, J. Li, Z. Hou, J. Liang, J. Zhou, Y. Zhu, Y, Qian, Ultrathin $\delta-\mathrm{MnO}_{2}$ nanosheets as cathode for aqueous rechargeable zinc ion battery. Electrochim. Acta 304, 370-377 (2019). https://doi.org/10.1016/j.electacta.2019.03.008

33. M.H. Alfaruqi, J. Gim, S. Kim, J. Song, D.T. Pham et al., A layered $\delta-\mathrm{MnO}_{2}$ nanoflake cathode with high zinc-storage capacities for eco-friendly battery applications. Electrochem. Commun. 60, 121-125 (2015). https://doi.org/10.1016/j.eleco m.2015.08.019

34. S.-D. Han, S. Kim, D. Li, V. Petkov, H.D. Yoo et al., Mechanism of $\mathrm{Zn}$ insertion into nanostructured $\delta-\mathrm{MnO}_{2}$ : a nonaqueous rechargeable $\mathrm{Zn}$ metal battery. Chem. Mater. 29(11), 4874-4884 (2017). https://doi.org/10.1021/acs.chemm ater.7b00852

35. R.A. Aziz, R. Jose, Charge storage capability of tunnel $\mathrm{MnO}_{2}$ and alkaline layered $\mathrm{Na}-\mathrm{MnO}_{2}$ as anode material for aqueous 
asymmetry supercapacitor. J. Electrochem. Soc. 799, 538-546 (2017). https://doi.org/10.1016/j.jelechem.2017.06.014

36. W.-J. Shi, Y.-W. Yan, C. Chi, X.-T. Ma, D. Zhang et al., Fluorine anion doped $\mathrm{Na}_{0.44} \mathrm{MnO}_{2}$ with layer-tunnel hybrid structure as advanced cathode for sodium ion batteries. J. Power Sources 427, 129-137 (2019). https://doi.org/10.1016/j.jpows our.2019.04.038

37. H. Xia, X. Zhu, J. Liu, Q. Liu, S. Lan et al., A monoclinic polymorph of sodium birnessite for ultrafast and ultrastable sodium ion storage. Nat. Commun. 9(1), 5100 (2018). https:// doi.org/10.1038/s41467-018-07595-y

38. K.W. Nam, S. Kim, E. Yang, Y. Jung, E. Levi, D. Aurbach, J.W. Choi, Critical role of crystal water for a layered cathode material in sodium ion batteries. Chem. Mater. 27(10), 37213725 (2015). https://doi.org/10.1021/acs.chemmater.5b00869

39. K.W. Nam, H. Kim, J.H. Choi, J.W. Choi, Crystal water for high performance layered manganese oxide cathodes in aqueous rechargeable zinc batteries. Energy Environ. Sci. 12(6), 1999-2009 (2019). https://doi.org/10.1039/C9EE00718K

40. P. He, G. Zhang, X. Liao, M. Yan, X. Xu, Q. An, J. Liu, L. Mai, Sodium ion stabilized vanadium oxide nanowire cathode for high-performance zinc-ion batteries. Adv. Energy Mater. 8(10), 1702463 (2018). https://doi.org/10.1002/aenm.20170 2463

41. J. Zhang, T. He, W. Zhang, J. Sheng, I.S. Amiinu et al., Na$\mathrm{Mn}-\mathrm{O}$ nanocrystals as a high capacity and long life anode material for Li-ion batteries. Adv. Energy Mater. 7(5), 1602092 (2017). https://doi.org/10.1002/aenm.201602092

42. Y. Park, S. Woo Lee, K.H. Kim, B.K. Min, A. Kumar Nayak, D. Pradhan, Y. Sohn, Understanding hydrothermal transformation from $\mathrm{Mn}_{2} \mathrm{O}_{3}$ particles to $\mathrm{Na}_{0.55} \mathrm{Mn}_{2} \mathrm{O}_{4} \cdot 1.5 \mathrm{H}_{2} \mathrm{O}$ nanosheets, nanobelts, and single crystalline ultra-long $\mathrm{Na}_{4} \mathrm{Mn}_{9} \mathrm{O}_{18}$ nanowires. Sci Rep. 5, 18275 (2015). https://doi.org/10.1038/srep1 8275

43. M.H. Alfaruqi, S. Islam, D.Y. Putro, V. Mathew, S. Kim et al., Structural transformation and electrochemical study of layered $\mathrm{MnO}_{2}$ in rechargeable aqueous zinc-ion battery. Electrochim. Acta 276, 1-11 (2018). https://doi.org/10.1016/j.elect acta.2018.04.139

44. M. Toupin, T. Brousse, D. Bélanger, Charge storage mechanism of $\mathrm{MnO}_{2}$ electrode used in aqueous electrochemical capacitor. Chem. Mater. 16(16), 3184-3190 (2004). https:// doi.org/10.1021/cm049649j

45. J. Li, J. Yu, I.S. Amiinu, J. Zhang, J. Sheng et al., Na-Mn$\mathrm{O} @ \mathrm{C}$ yolk-shell nanorods as an ultrahigh electrochemical performance anode for lithium ion batteries. J. Mater. Chem. A 5(35), 18509-18517 (2017). https://doi.org/10.1039/c7ta0 $6046 \mathrm{~g}$

46. S.-M. Hao, M.-Y. Yu, Y.-J. Zhang, Y. Abdelkrim, J. Qu, Hierarchical mesoporous cobalt silicate architectures as highperformance sulfate-radical-based advanced oxidization catalysts. J. Colloid Interface Sci. 545, 128-137 (2019). https:// doi.org/10.1016/j.jcis.2019.03.017

47. S.-M. Hao, J. Qu, W. Chang, Y.-J. Zhang, Y. Tang, Z.-Z. Yu, A high-performance dual-ion battery enabled by conversion-type manganese silicate anodes with enhanced ion accessibility.
ChemElectroChem 6(4), 1040-1046 (2019). https://doi. org/10.1002/celc.201801675

48. D. Lozano-Castelló, M.A. Lillo-Ródenas, D. Cazorla-Amorós, A. Linares-Solano, Preparation of activated carbons from spanish anthracite: I. Activation by $\mathrm{KOH}$. Carbon 39(5), 741749 (2001). https://doi.org/10.1016/S0008-6223(00)00185-8

49. Y. Sun, X. Hu, W. Luo, F. Xia, Y. Huang, Reconstruction of conformal nanoscale $\mathrm{MnO}$ on graphene as a high-capacity and long-life anode material for lithium ion batteries. Adv. Funct. Mater. 23(19), 2436-2444 (2013). https://doi.org/10.1002/ adfm.201202623

50. S.M. Hao, J. Qu, J. Yang, C.X. Gui, Q.Q. Wang, Q.J. Li, X. $\mathrm{Li}, \mathrm{Z} . \mathrm{Z}$. $\mathrm{Yu}, \mathrm{K}_{2} \mathrm{Mn}_{4} \mathrm{O}_{8} /$ reduced graphene oxide nanocomposites for excellent lithium storage and adsorption of lead ions. Chem. Eur. J. 22(10), 3397-3404 (2016). https://doi. org/10.1002/chem.201504785

51. N. Zhang, F. Cheng, J. Liu, L. Wang, X. Long, X. Liu, F. Li, J. Chen, Rechargeable aqueous zinc-manganese dioxide batteries with high energy and power densities. Nat. Commun. 8(1), 405 (2017). https://doi.org/10.1038/s41467-017-00467-x

52. L. Chen, Z. Yang, H. Qin, X. Zeng, J. Meng, Advanced electrochemical performance of $\mathrm{ZnMn}_{2} \mathrm{O}_{4} / \mathrm{N}$-doped graphene hybrid as cathode material for zinc ion battery. J. Power Sources 425, 162-169 (2019). https://doi.org/10.1016/j.jpows our.2019.04.010

53. R. Shannon, Revised effective ionic radii and systematic studies of interatomic distances in halides and chalcogenides. Acta Cryst. 32(5), 751-767 (1976). https://doi.org/10.1107/S0567 739476001551

54. J. Huang, Z. Wang, M. Hou, X. Dong, Y. Liu, Y. Wang, Y. $\mathrm{Xia}$, Polyaniline-intercalated manganese dioxide nanolayers as a high-performance cathode material for an aqueous zinc-ion battery. Nat. Commun. 9(1), 2906 (2018). https://doi. org/10.1038/s41467-018-04949-4

55. T. Wei, Q. Li, G. Yang, C. Wang, Pseudo-Zn-air and Zn-ion intercalation dual mechanisms to realize high-areal capacitance and long-life energy storage in aqueous $\mathrm{Zn}$ battery. Adv. Energy Mater. 9(34), 1901480 (2019). https://doi.org/10.1002/ aenm.201901480

56. Y. Huang, J. Mou, W. Liu, X. Wang, L. Dong, F. Kang, C. $\mathrm{Xu}$, Novel insights into energy storage mechanism of aqueous rechargeable $\mathrm{Zn} / \mathrm{MnO}_{2}$ batteries with participation of $\mathrm{Mn}^{2+}$. Nano-Micro Lett. 11(1), 49 (2019). https://doi.org/10.1007/ s40820-019-0278-9

57. F. Liu, Z. Chen, G. Fang, Z. Wang, Y. Cai, B. Tang, J. Zhou, $\mathrm{S}$. Liang, $\mathrm{V}_{2} \mathrm{O}_{5}$ nanospheres with mixed vanadium valences as high electrochemically active aqueous zinc-ion battery cathode. Nano-Micro Lett. 11(1), 25 (2019). https://doi. org/10.1007/s40820-019-0256-2

58. L. Shan, Y. Yang, W. Zhang, H. Chen, G. Fang, J. Zhou, S. Liang, Observation of combination displacement/intercalation reaction in aqueous zinc-ion battery. Energy Storage Mater. 18, 10-14 (2019). https://doi.org/10.1016/j.ensm.2018.08.008

59. Q. Zhang, M.D. Levi, Q. Dou, Y. Lu, Y. Chai et al., The charge storage mechanisms of $2 \mathrm{D}$ cation-intercalated manganese 
oxide in different electrolytes. Adv. Energy Mater. 9(3), 1802707 (2019). https://doi.org/10.1002/aenm.201802707

60. Q.T. Qu, Y. Shi, S. Tian, Y.H. Chen, Y.P. Wu, R. Holze, A new cheap asymmetric aqueous supercapacitor: activated carbon// $\mathrm{NaMnO}_{2}$. J. Power Sources 194(2), 1222-1225 (2009). https ://doi.org/10.1016/j.jpowsour.2009.06.068
61. B.H. Zhang, Y. Liu, Z. Chang, Y.Q. Yang, Z.B. Wen, Y.P. Wu, R. Holze, Nanowire $\mathrm{Na}_{0.35} \mathrm{MnO}_{2}$ from a hydrothermal method as a cathode material for aqueous asymmetric supercapacitors. J. Power Sources 253, 98-103 (2014). https://doi. org/10.1016/j.jpowsour.2013.12.011 